\title{
How does teacher professional development support and improve technology teacher practice?
}

\section{Bruce Granshaw}

December 2010

Three paper thesis in partial fulfilment of the requirements of the

Master of Education 


\begin{abstract}
The development and implementation of the New Zealand Curriculum in 2007 and the introduction of standards-based assessment, in the form of achievement standards, has necessitated a raft of changes for technology teachers. Professional development is widely considered to be of value in developing teacher knowledge which can positively impact on student knowledge and achievement. While there is a considerable body of research on professional development, there is a limited amount specific to technology education professional development in a New Zealand context. This thesis is based on an examination of the nature and characteristics of effective professional development for technology teachers. It used a qualitative, interpretive design and gathered data by interviewing a group of ten technology teachers and heads of technology departments from different schools in one region. The interview data were transcribed and sorted using inductive content analysis in order to categorise them and draw conclusions. The findings indicate that there is a wide range of characteristics which may be considered effective for technology teachers in this study, and foremost, the opportunity for teachers to work collaboratively in examining programmes, student work, resources and exemplars, such that teachers can build on their existing knowledge and skills, is most effective for them. The development of pedagogical content knowledge and subject content knowledge enabled the teachers to construct new understandings of teaching and student learning processes in technology education. The implications of this study are that facilitators, teachers, and others working within this curriculum area may be informed by its findings and as a result, professional development may be more effective in supporting teacher learning.
\end{abstract}




\section{Acknowledgements}

There are a number of people who have supported me in undertaking this research study. I am very grateful and would like to thank you all for your advice, positivity and encouragement.

My supervisors, Dr. Louise Starkey and Dr. Catherine Savage for your advice and guidance; Staff members of Victoria University Faculty of Education, who have provided timely advice when most needed; Dr. Robert Strathdee for your encouragement and support.

Professor Cedric Hall for your expertise and discussion.

Technology teachers, and principals of schools on which I based my data collection, without whose cooperation this study could not have been undertaken.

Dr Vicki Compton and Cliff Harwood for your advice and support.

Finally, my partner and family who have showed patience and support throughout the whole academic process. 


\section{Table of Contents}

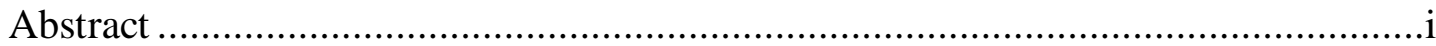

Acknowledgements........................................................................................ ii

Chapter One: Introduction........................................................................................1

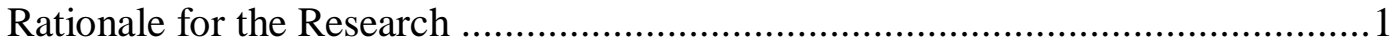

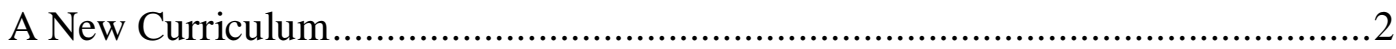

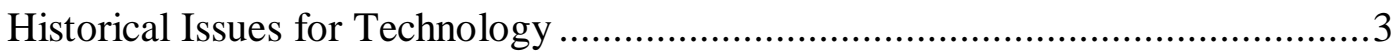

Chapter Two: Literature Review ...................................................................6

What Works in Professional Development …................................................6

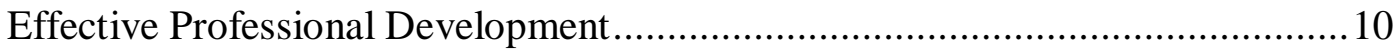

Evaluating the Effectiveness of Professional Development.............................. 13

Collaboration and Learning Communities ............................................................ 17

Types and Duration of Professional Development ............................................21

Leadership and Facilitation ....................................................................22

Improved Student Learning ................................................................. 24

Pedagogical Content Knowledge ..............................................................26

Key Considerations of Effective Professional Development .............................27

Technology in the New Zealand Curriculum ...................................................28

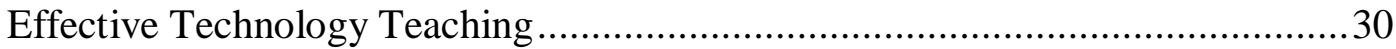

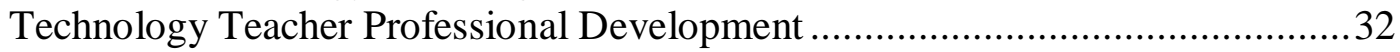

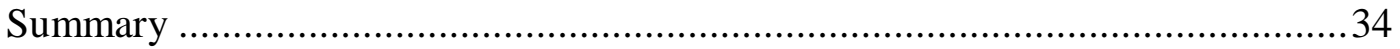

Chapter Three: Methodology …..................................................................................35

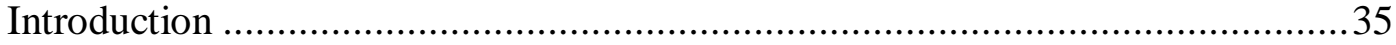

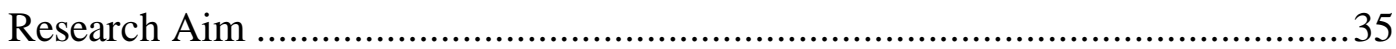

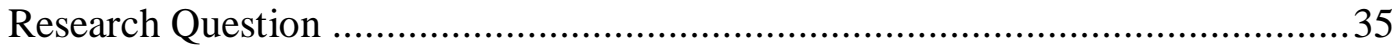

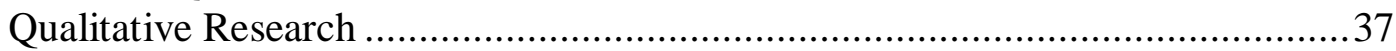

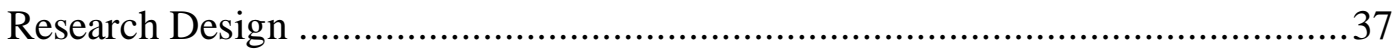

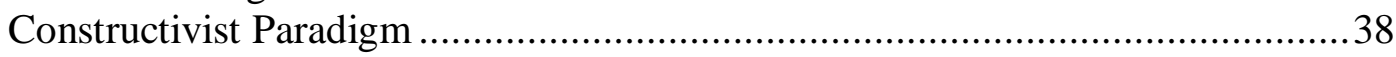

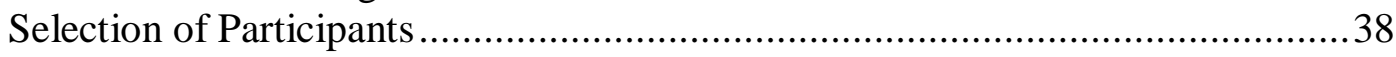

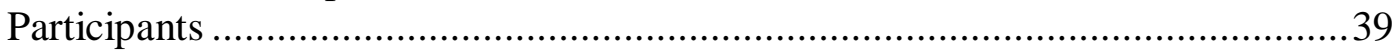

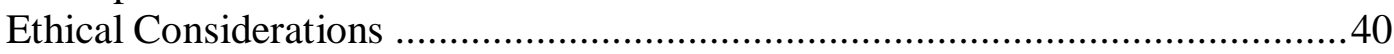

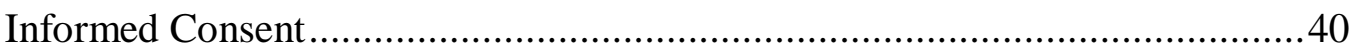

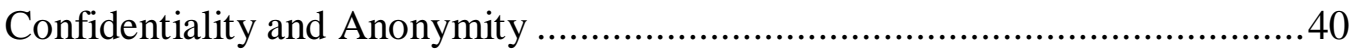

Data Collection Procedures ............................................................................ 40

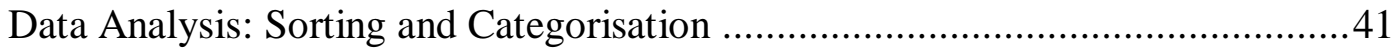

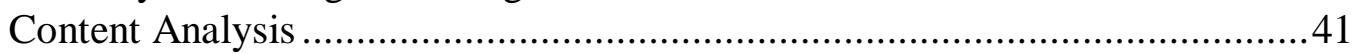

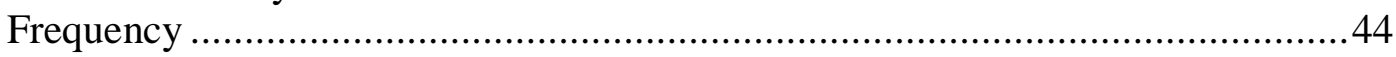

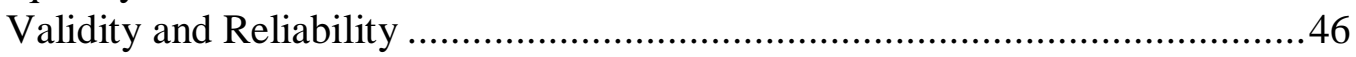

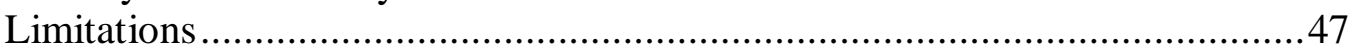

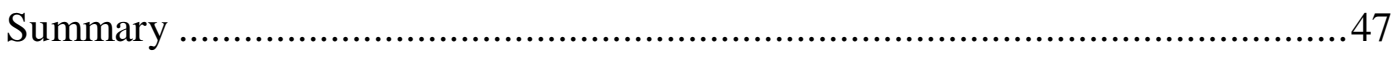


Chapter Four: Findings...............................................................................................49

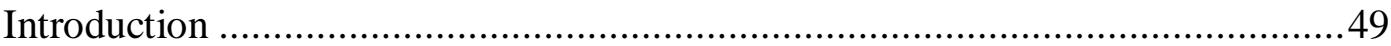

Summary of classification of responses into categories ..................................49

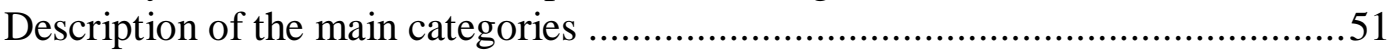

Analysis of data and research findings ....................................................5

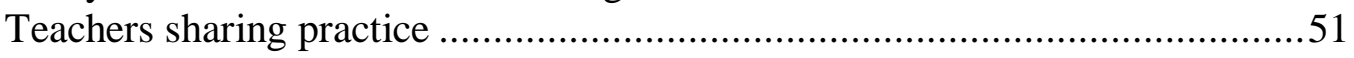

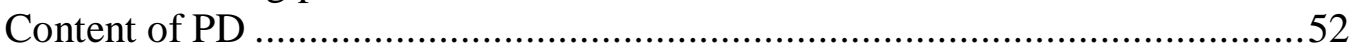

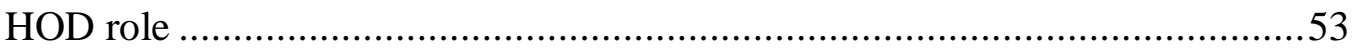

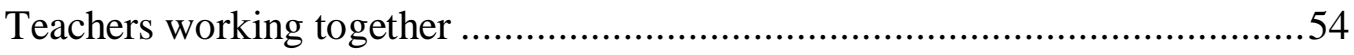

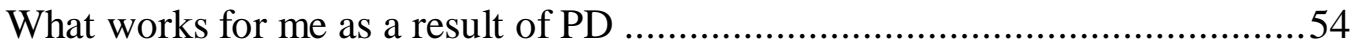

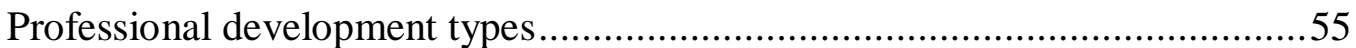

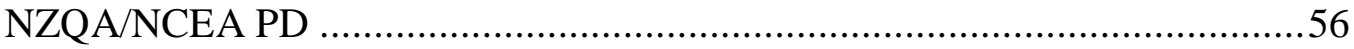

Professional development facilitator practice ..............................................57

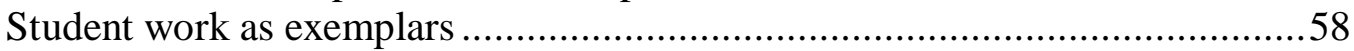

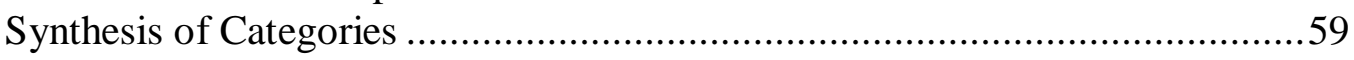

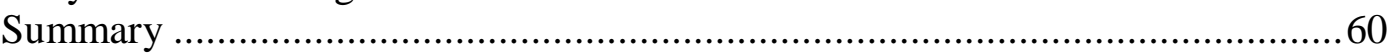

Chapter Five: Discussion ................................................................................61

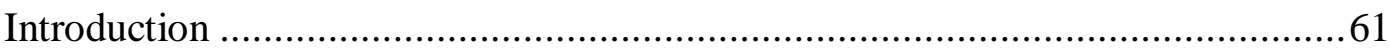

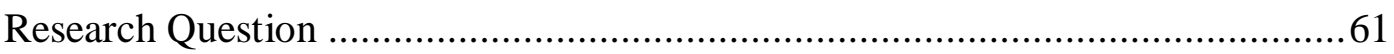

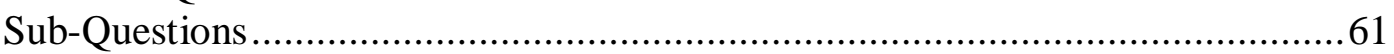

How can technology teachers best be supported in their development and

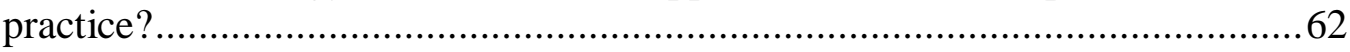

What forms of professional development do technology teachers consider best supports and improves their practice? .................................................65

In what ways do technology teachers view that effective professional development contributes to their practice?

To what extent does teacher professional development facilitator (TPDF) practice influence the effectiveness of the professional development?

What do heads of technology departments regard as most effective in supporting their technology teachers with changing their practice? ................ 70

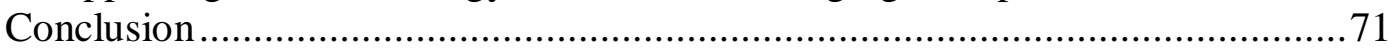

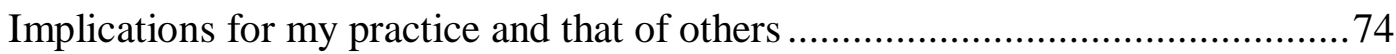

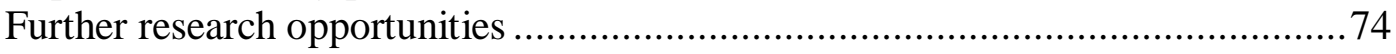

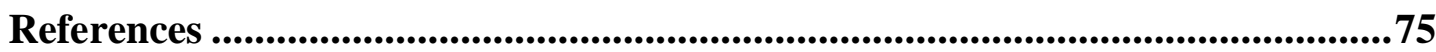

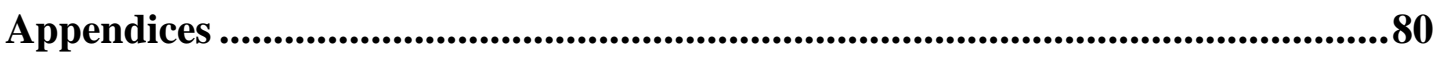

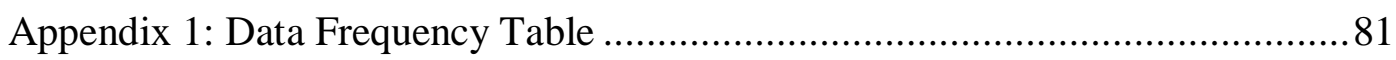

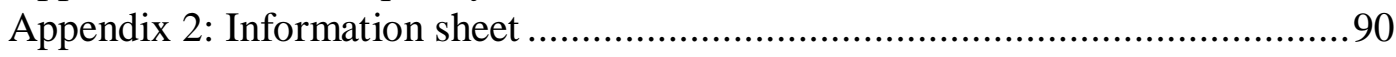

Appendix 3: Consent form for participating teachers ....................................92 


\section{List of Tables}

Table 2.1: Kirkpatrick's four-level evaluation model.......................................... 14

Table 2.2: Guskey's five level evaluation model................................................. 16

Table 2.3: Links between key considerations and sub-questions ..........................27

Table 2.4: Technology specific teacher knowledge ..............................................30

Table 2.5: Requirements for effective teaching of technology in New Zealand .......31

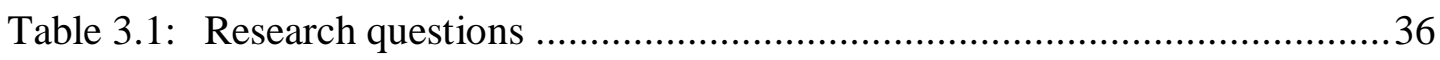

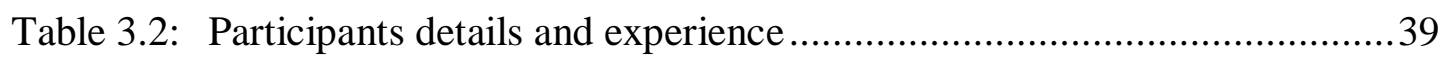

Table 3.3: Sample transcript and coding .......................................................43

Table 3.4: Frequency table (part) showing content units, categories and frequency ....45

Table 4.1: Rank order, categories, frequency and percentage of total ....................50

Table 4.2: Description and categories showing percentages and totals ..................59 


\section{Chapter One: Introduction}

The purpose of this research was to develop understandings to inform the professional development (PD) of technology teachers in a New Zealand context. While there is a wide range of literature and research into teacher PD generally, for example, Timperley, Wilson, Barrar \& Fung (2007), Poskitt (2005), Ingvarson, Meiers \& Beavis (2005), there is limited research and knowledge about PD specifically for technology teachers.

\section{Rationale for the Research}

My role during the last eight years has been that of technology adviser working with technology teachers, middle and senior management, and others within the sector, facilitating PD in technology education. This has provided an opportunity to gain considerable understanding of issues concerning technology PD and its facilitation, as well as insights into technology teachers' perspectives of professional support in this curriculum area.

The implementation of the New Zealand Curriculum (Ministry of Education, 2007a) in 2010 has necessitated a focus for all technology teachers on student learning in technology, and the development and delivery of effective programmes of teaching and learning. Ferguson (2008) suggested that effective implementation of the technology learning area of the New Zealand curriculum will be dependent on "school principals and senior management having an understanding of technology education ... and teachers being knowledgeable, passionate and excited about technology education" (p. 51). He considered that technology advisers who develop and facilitate PD "have a vital role to play in supporting teachers" (p. 51).

The aim of this research was to find out from technology teachers how teacher PD can support and improve their practice. It was anticipated that a better understanding of what was effective for teachers in this context will not only support them at a time of major curriculum change, but will also support and improve my practice as a PD facilitator, and that of others, working in the field of technology education. 


\section{A New Curriculum}

The Ministry of Education published the New Zealand Curriculum (Ministry of Education, 2007a) to set the direction for learning for all students from years $1-13$ in English medium New Zealand schools. It was developed as part of the New Zealand Curriculum Marautanga Project which progressed from the findings of the New Zealand Stocktake Report (Ministry of Education, 2002). Eight essential learning areas, of which Technology is one, provided an interconnected structure which forms the basis for students' general education. Specialisation at senior levels is supported by this foundational structure. The intention of the curriculum is that learning within these areas is not mutually exclusive, rather that opportunities should be exploited which connect learning across and between these areas, thereby supporting development of a set of Key Competencies and Values.

The purpose of technology education, as described in its own essential learning area within the New Zealand Curriculum, is to develop students' technological literacy. This occurs when students engage with the three types of transformations seen to be at the core of learning in this subject - those of energy, materials, and information. A broad technological literacy gives students the ability to "participate in society as informed citizens and give them access to technology related careers" (Ministry of Education, 2007a, p. 32).

The technology essential learning area within the curriculum is structured around three strands and eight achievement objectives. The Technological Practice strand contains three achievement objectives: Brief Development; Planning for Practice; and Outcome Development and Evaluation. This strand may be considered to be a 'know how' strand which provides a framework for the development and critique of technological outcomes by means of students engaging in technological practice. The Technological Knowledge strand is also structured around three achievement objectives: Technological Modelling; Technological Products and Technological Systems. This 'know that' strand supports technological practice by developing in students the ability to consider the feasibility and desirability of technological outcomes in a societal context. It also supports the development of technological knowledge in its own right, allowing for a more informed, deeper, wider 
technological literacy to be developed. The third 'know why' strand, Nature of Technology, contains two achievement objectives: Characteristics of Technology and Characteristics of Technological Outcomes. It supports the practice taking place by developing in students more critical and informed decision making both within and outside their technological practice. It also provides a "critical understanding of technology as an intervening force in the world" (Compton, 2007, p. 15) and that historical, social and cultural aspects of society influence and are influenced by technological developments.

The Ministry of Education has recognised a need for effective PD and supporting resources for technology teaching by providing a significant level of research funding. Outcomes from the research and resource development, which is in progress, are intended to support teachers with the implementation of both the curriculum and the technology essential learning area. The changes for teachers, required as a result of the introduction of the revised curriculum and the technology learning area, mean that this research is not only timely, but its findings may be used to inform the PD which will support them.

\section{Historical Issues for Technology}

Ministry of Education policy, in part driven by international developments and global trends, as well as the changing needs of the New Zealand economy and society, has facilitated a significant transformation of technology education. This may be seen as having three distinct phases: Pre-1975 Technical Education; 1975 1992 Technical/Technology Education; and 1993 to the present day Technology Education. These transformations have had a major impact on teacher understanding of the subject (Harwood \& Compton, 2007). In particular, many teachers who were involved in teaching craft-based 'technical' education were being required to teach 'technology' education, and it seems many do not necessarily feel confident to do so. These teachers have been managing a major shift in both the structure of the subject and the pedagogy. Technical education tended to be taught using predominantly behaviourist-based teaching practices. Technology education requires a "sophisticated mix of sociocultural and constructivist-based practices" (Harwood \& Compton, 2007, p. 113), which draw significantly on social, ethical, moral and 
cultural factors. As a result of this shift it seems the technology community has 'factionalised' to an extent, with teachers in some schools who were teaching craftbased subjects not necessarily engaging with new approaches, content and pedagogies. It may be that some students have been disadvantaged due to this tension within the subject, where programmes are not aligned to recent curriculum developments and assessment opportunities.

The developments, therefore, are not only associated with the structure and philosophical basis for technology education but also with assessment. The introduction of the National Certificate of Educational Achievement (NCEA) and standards-based assessment in 2002 has also challenged many teachers. Nixon (2004) discusses the introduction of NCEA as changing how students are assessed and teachers' understanding of pedagogy, learning and knowledge. This may be especially applicable to teachers who have not developed a clear understanding of technology education and therefore not developed the types of technology programmes they teach. Students following prescriptive craft/technical-based programmes may have been disadvantaged in accessing many of the achievement standards associated with technology if they do not have the necessary background knowledge and competencies appropriate to curriculum level 6, a necessary requirement of NCEA Level 1 technology achievement standards. This could lead to some teachers in this position believing that technology education is too 'academic' for their students and therefore not appropriate, or else technology achievement standards just do not work for them as assessment tools.

Extensive PD is seen by many (Ferguson, 2008; Harwood \& Compton, 2007; Jones, 2003) as the most important aspect of future development of teacher understandings of technology education. For many teachers of technology it is a new subject which bears little, if any, resemblance to that which they have been trained to teach. The effectiveness of PD is critical in that it needs to be relevant to teacher requirements, and manageable for them.

The Inservice Teacher Education Practice (INSTEP) project, a New Zealand Ministry of Education research and development initiative, examined the practice of PD facilitators. It involved nearly four hundred inservice teacher educators and 
researchers between 2005 and 2008 and had three key objectives: "to explore and develop effective approaches for the professional learning of inservice teacher educators; to strengthen and promote evidence-based inservice teacher education practice; and to support professional leadership and ongoing improvement within the inservice teacher educator sector" (Ministry of Education 2008, p. 15). A set of learning materials was produced as a result of this research, and consideration was given to what was known both nationally and internationally about effective PD facilitation and learning. The research accepts that teacher PD facilitators have a complex and changing role that needs to support teachers and impact positively on student achievement (Ministry of Education, 2008). In doing this, facilitators support the government's priorities of building an education system that equips New Zealanders with $21^{\text {st }}$ century skills as well as reducing underachievement for particular groups of students by "focussing effort on strengthening effective teaching, including effective relationships between schools and homes that work for teachers and whānau, and on incorporating practices into all teacher education that are effective for Māori students" (Ministry of Education, 2005, p. 13).

This research examined what constitutes effective PD generally. It considers how PD may be evaluated in terms of its effectiveness, how PD facilitators work, and what factors are most effective for technology teacher learning that impact positively on student learning. It adds to the INSTEP findings by examining the nature of the PD rather than just focusing on the practice of facilitators themselves, and also adds to other key research such as Teacher Professional Learning and Development Best Evidence Synthesis Iteration (Timperley et al., 2007) by providing a specific focus on technology teacher learning and development. It is intended, therefore, that it may be of use to the Ministry of Education and also to principals and PD facilitators of technology. 


\section{Chapter Two: Literature Review}

A review of literature indicates that there is a wide range of research on teacher PD both internationally and in New Zealand. However, it seems there is less available which focuses specifically on PD for technology teachers in the New Zealand context.

A synthesis of research literature by Alton-Lee (2003) indicates that teachers' knowledge and practice is the most critical element in improving learning for diverse students, and reducing the disparity between high and low student achievement. Timperley et al. (2007), in their Teacher Professional Learning and Development Best Evidence Synthesis Iteration [BES], developed a theoretical framework with more than eighty characteristics that linked teacher PD with a wide range of student outcomes including personal and social as well as academic. The theoretical framework was developed as a result of a national and international search for studies which had a focus on student achievement. They identify limitations to their framework by recognising that often teacher learning, and therefore improved student outcomes, can be informal, during and after school. This kind of teacher learning is generally not documented and therefore is not part of the synthesis, but is still recognised as important and effective. The authors found that "opportunities for teachers to engage in professional learning and development can have a substantial impact on student learning" (p.xxv). The type of PD which teachers experience can be either short one-off workshops run by facilitators and often featuring inspirational speakers, or there can be an extended timeframe with multiple meetings and learning opportunities. In the United States, the former is more common as described in the National Staff Development Council (2001), and conferences and one-day workshops are also common in New Zealand; however, a wide range of factors other than type and duration, which impact on the effectiveness of PD for teachers, will be explored in this review of literature.

\section{What Works in Professional Development}

When considering whether PD for teachers is effective and 'works' it is necessary to be clear about what is meant by this. Timperley et al. (2007) consider effective professional learning, as a result of $\mathrm{PD}$, to be that which supports effective learning 
for students. They have developed a framework for analysing the effectiveness of professional learning experiences in terms of positive impact on student learners. The framework identifies two contexts interacting within this professional learning. The 'wider social context' includes formal education policies and curriculum, prevailing discourses, and social organisation. The 'professional learning context' within it considers people and practices and professional learning goals. The content of the PD learning opportunity and the activities within it, which have been constructed by the facilitator to promote teacher learning, lead to learning processes and responses of participants, which in turn has a direct impact on diverse student learners.

It should be noted, however, that opportunities for professional learning are varied and therefore the authors' theoretical framework has limitations, namely that much professional learning occurs outside of formal PD sessions, at meetings during and after school. This aspect is important as it is common for cluster and subject association meetings to provide information and support for teacher learning.

Timperley et al. (2007) found there were four important aspects of PD which they termed overviews, and each contained a number of elements. These were context, content, activities which promote learning, and learning processes. They may be summarised as follows. Context for professional learning included allowing enough time, using external expertise and placing focus on learning processes for participants. The content for professional learning and development included linking learning theory to teaching practice in the classroom, understanding the role assessment has in teaching and learning, and the need to sustain changed practice after the PD has concluded. Activities which support professional learning included there being a range of practical activities available which clearly linked to the content, and that participants had the opportunity to discuss these and share ideas, rather than just listening to a facilitator. Also important here was the existence of a structure which linked rationale, theory, teaching practice and student learning. Learning processes was concerned with challenging existing knowledge and beliefs whilst absorbing new theoretical understandings.

Timperley et al. (2007) recognised that teachers have a wide range of learning needs which depend on their prior knowledge, skills, and dispositions, and also have to 
manage frequent and ongoing change in terms of curriculum development and associated pedagogy. They construct a theoretical sequence of learning where professional learning opportunities lead to teacher outcomes and change in practice. This in turn leads to student learning opportunities and change in student outcomes. The synthesis identifies two 'black boxes', one between teacher learning opportunities and outcomes, and the other between student learning opportunities and outcomes. These black boxes represent the "interpretation and utilisation of available understandings and skills" (p. 7) on the part of both the teacher and the student. The synthesis explores what takes place in these black boxes and how it occurs. Professional learning opportunities may or may not lead to a change in teacher practice, so what actually occurs within the black box is important to understand if positive change is to be assured. The same applies to student learning opportunities and resulting outcomes. The relationship between the teaching process and students' learning has been the subject of much investigation (Alton-Lee, 2003; Atkin, 1996; Cheetham \& Chivers, 2000); however, examination of the processes which occur between teacher PD and changes in teaching practice is much less understood. It is this which is a primary focus of the research underpinning the synthesis. Timperley et al. (2007) conclude that "the most powerful professional development for teachers involves them in an inquiry and knowledge cycle that starts with the identification of students' needs, moves to develop the knowledge and skills teachers require to meet those needs, and then checks to find out if changes in teaching practice have achieved the desired results" (cited in Ministry of Education, 2008, p. 10).

Hill, Hawk and Taylor (2002) describe specific research undertaken in 2000 by the Institute of Professional Development and Educational Research (IPDER) which was contracted by the Ministry of Education to examine a range of schools' PD practices and compare these to what the literature considers to be effective. The sample of schools comprised a mix of primary, intermediate and secondary, across all deciles (socio-economic background of students' families) and of varying sizes. Data were collected from a wide range of sources, mainly by questionnaire. School evaluations of existing practice, evaluations by PD providers and by participating principals all formed the basis for the data analysis. A comprehensive review of international literature identified seven characteristics of effective PD: 
1) Learning is for everyone - where there is an assumption that even in the most effective schools the changing context of education requires a commitment to learning on the part of both teachers and principal. Timperley et al. (2007) found that teacher engagement was more important than if teachers volunteered or were compelled to participate in PD. It follows, therefore, that if all teachers engage with PD there is likely to be a bigger impact on student learning.

2) We learn by taking risks and trying something new - where it is considered that teachers need to feel 'safe' in taking risks and evaluating their learning and practice in a supportive environment. This is supported by DuFour (2004) who discusses the fact that teachers working collaboratively are able to support each other with the challenges of new learning. Timperley et al. (2007) refer to a supportive learning environment differently; they identify active school leadership in terms of it supporting effective teacher learning.

3) We need to own the process - where Rudman (1999) considers that teachers will not engage with the learning if they feel they are being talked down to or treated with a lack of respect. The PD needs to be structured such that participants feel they are part of it rather than having it imposed upon them. This is in line with Timperley et al. (2007) who found that a structure which links theory and practice is a key aspect of effective PD and that teachers need to be assisted in transferring learning into classroom practice for them to feel they have ownership of the process.

4) The learning needs to be relevant - where Willis (2000) considers that the PD content needs to be relevant to teachers' needs and be related to the environment in which they teach. Relating the professional learning to the type of community, school and students is essential for effective change to occur.

5) We need to focus on deep rather than shallow learning - Hill et al. (2002) consider that the focus for professional learning needs to be on more than just providing understandings and experiences which allow teachers to make changes to their practice; it also needs to support them in "examining the values and beliefs which underpin the practice" (p. 4).

6) We're working on this together - this considers the school being a learning community where teachers, students, and parents collaborate with the common 
goal of improved student outcomes. Further to this, teachers need to communicate and network with their peers both within and across schools in order to evaluate strategies and knowledge they gain through participation in PD.

7) What difference is this making to our students? - Showers and Joyce (1996) suggest "Teachers need to plan how they will monitor implementation of the new initiatives and how they will determine the impact of each initiative on their students" (as cited by Hill et al., 2002, p. 5). This is also supported by an Education Review Office (2009) survey which finds lack of evidence for evaluation of PD and its impact on teaching and learning. But as stated earlier, there is a black box between PD and student learning that is very hard to unpack.

The IPDER research identified sixteen aspects of PD as a result of analysing data gathered, and much of it aligned with the findings of the literature review above. However, this research did not look at improved outcomes for students due to the relatively short time span. The data were gathered over a 15 -month period and did not focus on measuring improved student achievement. Most literature and research, including this, agree that effective PD needs to be linked to improved student achievement; however, research which gathers reliable data on improved student achievement needs to be longitudinal and this is not evident in the search of literature.

Hill et al. (2002) conclude that PD for all teachers is "vital in ensuring that a school is a vibrant learning community for teachers and students" (p. 15). The IPDER research shows that having the PD on site rather than at an alternative venue, where teachers can more easily access collegial support, is highly effective. The point here is that teachers value working together to develop and evaluate their understandings. There are circumstances, however, where teachers need to work with colleagues from the same curriculum area for this deeper understanding to occur. In this case working off site with other specialist teachers can be more effective.

\section{Effective Professional Development}

The content, structure and facilitation of PD as well as improved student outcomes, may be only part of the picture when we consider the effectiveness of the learning (Hill et al., 2002; Timperley et al., 2007). Salas and Cannon-Bowers (2001), in their 
extensive review of literature on the subject of training and PD, found that new knowledge in "cognitive and organisational concepts, is revolutionising the field" (p. 490). This is in line with work by Timperley, Parr and Bertanees (2009) who considered that "approaches to professional development have either focussed on developing better prescriptions for teacher practice or on collaborative reflective enquiry into practice" (p. 228). They discuss a third approach where teachers identify their learning needs themselves and that they do this by examining their students' learning needs. This allows teachers to build a depth of pedagogical knowledge which, when implemented and evaluated, demonstrates improving student learning. They consider that prescriptive approaches to PD often have limited outcomes which may lead to improved student performance in the short term, but teachers may not acquire the deeper learning which can lead to sustained student improvement over longer periods of time.

Timperley et al. (2009) also recognise that PD commonly supports teachers to engage in professional learning communities and for them to develop collaborative enquiry processes. They conclude, however, after a major search for information and literature over the last forty years focussed on student outcomes that there is little evidence of improved student outcomes as a result. It may not be that student learning has not improved, more that limited research has focused on student achievement as a result of teacher PD, therefore very little is known about it.

Two other key reports prepared for the New Zealand Ministry of Education investigate what is effective PD. Mitchell and Cubey (2003), in their best evidence synthesis, identify a number of key characteristics of effective PD for early childhood teachers (p. 81). Those relevant to this study include:

- The PD incorporates participants' own aspirations, skills, knowledge and understanding into the learning context. This is supported by a range of literature, including Starkey et al. (2006) who found an aspect of effectiveness was recognition of participants' prior knowledge and experience, and Timperley et al. (2007) who found that new understandings could be built upon existing theoretical understandings, although difficulties could arise if those existing understandings were flawed. 
- The PD provides theoretical and content knowledge and information about alternative practices. This is in line with Timperley and Robinson (2001) who considered the links between teachers' knowledge about alternative practices, and their theoretical understandings. They found a critical aspect was that teachers needed to be supported with data collection and analysis to make explicit the required changes to practice.

- Critical reflection enabling participants to investigate and challenge assumptions and extend their thinking is a core aspect. Hill et al. (2002) also found that professional learning is supported by challenging existing values, beliefs and assumptions. Timperley et al. (2007), however, identify a risk of disengagement for some participants sensitive to the challenges to their existing beliefs in terms of content and pedagogy.

- The PD helps participants to change educational practice, beliefs, understanding, and/or attitudes. Garet, Porter, Desimone, Birman and Yoon (2001) examined the links between PD and teacher change in practice. They identify that a combination of both structure and content of PD have a beneficial effect on the desired outcome of teacher change.

Although this BES is focused on early childhood teachers, there is much which is general to secondary teacher PD. For example, PD is effective if the learning builds on teachers' existing knowledge and embraces their aspirations and contexts. Hill et al. (2002) and others, as cited above, also found that relevance to teachers' needs and their teaching contexts of community, school and types of students is a critical aspect of effective PD. Further to this, that teachers need to engage in critical reflection of their own practice by means of examining the values and beliefs that underpin their practice.

Salas et al. (2001) conducted a broad review of the research literature on training and development. Their article identifies that there has been "an explosion of theoretical, methodological, and empirical work in training research" (p. 489) and that the knowledge gained from this will support training, and in an educational context, PD, to be more effective. Further to this they conclude that the use of technology has had a significant impact on the design and delivery of PD. They make the point that using 
technology just for delivery may not be particularly beneficial, but with the development of more sophisticated and 'intelligent' learning systems, virtual environments and web-based training systems, effectiveness of PD may be enhanced.

In the Ministry of Education Report Review of Secondary Schools' use of NCEA PD resources, 2005 - 2006, Starkey et al. (2006) conducted a brief literature review with a focus on identifying important aspects of PD and its effectiveness. Their aim was to look for what could be adapted to the specific area of NCEA. Five aspects were identified:

- Learning theory was important and that planning and facilitating PD needed to embrace "implicit theories of training and learning and communicate these to participants" (p. 10). Salas et al. (2001) recognise this in terms of the importance they place on cognitive and organisational theory.

- Participants' self assessment of their learning needs is critical. Designers of PD need to access this information to ensure the programme is relevant.

- Facilitators need to identify the prior knowledge and experience of participants and construct the learning in a way that will be motivating, and engage them.

- The format of the programme should allow for participants to work in teams such that they can share learning experiences and participate in a constructive peer feedback process.

- The programme should support a formative assessment element and opportunity for participants and facilitator to evaluate both the programme and the learning.

This report adds further to a notion emerging from the literature that a wide range of factors constitute effectiveness in PD; identifying which factors are most important includes consideration of the outcomes required as a result of participating in the learning.

\section{Evaluating the Effectiveness of Professional Development}

Salas et al. (2001) see a clear distinction between effectiveness and evaluation in training. They consider that effectiveness is concerned with why the learning works, the method used, and "how the training (and learning) is positioned, supported and 
reinforced by the organisation" (p. 490). Evaluation, however, is concerned with examining what works. "It looks at what was learned at different levels, and is the basis for determining the training effectiveness of a particular intervention" (p. 491).

Kirkpatrick's (1976) work on identifying a four-level evaluation model is considered by many as a key work in the field. It was developed through his work on training and development which began as early as 1959. He identified four levels which together form a framework for the evaluation of programmes of training and PD. These form a progressive hierarchy and become increasingly complex and time consuming; however, more valuable information is gained as complexity increases.

Table 2.1: Kirkpatrick's four-level evaluation model

\begin{tabular}{ll}
\hline Reaction & of the participants \\
Learning & which had taken place \\
Behaviour & $\begin{array}{l}\text { where there had been a change in the practice of participants } \\
\text { Results }\end{array}$ \\
& \begin{tabular}{l} 
which the participants had come. \\
\hline
\end{tabular}
\end{tabular}

Kirkpatrick discussed reasons for evaluating training and concluded that most important is the need to gauge the effectiveness of a programme and whether there are any ways in which it might be improved and, if so, how. He identified eight factors of particular relevance:

- To what extent does the subject content meet the needs of those attending?

- Is the leader the one best qualified to teach?

- Does the leader use the most effective methods for maintaining interest and teaching the desired knowledge, attitudes and skills?

- Are the facilities satisfactory?

- Is the schedule appropriate for the participants?

- Are the aids effective in improving communication and maintaining interest?

- Was the coordination of the programme satisfactory?

- What else can be done to improve the programme? (Kirkpatrick, 1976, p. 17)

The data gathered from addressing these eight questions can support future planning and delivery of training programmes. 
Kirkpatrick's model was accepted and adopted rapidly by organisations concerned with training, especially in the field of industrial organisation. The strength of it was its simplicity and its ability to focus on criteria for evaluation. It provided a vocabulary and taxonomy for criteria; however, it has been criticised by Alliger \& Janak (1989) as being prone to "assumptions which can tend to misunderstandings and over generalisations" (p. 332). Holton (1996) also criticises Kirkpatrick's model as a taxonomy which, like all taxonomies, does not "fully identify all constructs underlying the phenomena of interest, thus making validation impossible" (p. 6). He further considers that the relationship between each level of the taxonomy is not research based as Allinger and Janak (1989) found as a result of their literature review going back as far as 1959. However, Kirkpatrick's work has provided a basis on which others have built, for example, Praslova (2009) has developed an adaptation of Kirkpatrick's model to suit evaluation in higher education. This adaptation clarifies the criteria and creates plans for the evaluation of educational outcomes. The model links the original organisational training criteria to learning in higher education and provides corresponding sample instruments and indicators. She concludes that the use of an adapted Kirkpatrick model in a higher education context "can provide colleges and universities with a versatile tool for creating and refining their evaluation and assessment systems" (p. 10). It can also be of value in evaluating short and long-term organisational outcomes.

In a school-based context, Guskey (2000) proposed a model for evaluating PD which builds on Kirkpatrick's earlier work. He considers that there is a range of PD practice, some of which is effective and some not. He suggests that there are five critical levels of evaluation which enable us to judge the effectiveness of a programme. These are shown in Table 2.2 below. 
Table 2.2: Guskey's five level evaluation model

\section{Level 1}

Participants' Reactions

Level 2

Participants' Learning

\section{Level 3}

Organisational Support and

Change

\section{Level 4}

Participants' Use of New

Knowledge and Skills

\section{Level 5}

Student Learning Outcomes considered whether participants enjoyed the PD, if it made sense to them, if they felt it would be useful and whether they had confidence in the presentation.

considered assessment of the knowledge and skills participants gained in the context of classroom application.

concerned schools supporting the professional development by adapting and developing policies which supported the proposed changes. This might be within departments or school wide depending on the context of the professional development.

questioned whether the new knowledge and skills made a difference to professional practice after these had been contextualised and implemented.

addressed the effect the changed practice had on student learning depending on the goals of the specific professional development.

Guskey accepted that using his five level plan will not necessarily provide proof that the PD has made a difference to student achievement because the complexities of teacher learning impacting on student learning introduces too many variables. He suggests, however, that a range of 'evidence' may be gathered based on the clear outcomes and goals identified at the start of the evaluation. Guskey considers effective evaluation of PD should be planned with a primary focus on what is to be achieved in terms of learning for participants, rather than how it is managed and what activities learners undertake.

Guskey and Sparks' (Guskey, 2000) model of the relationship between PD and improvements in student learning clarifies that the content characteristics, or the 'what' of a PD programme, along with the process variables or the 'how', and the context characteristics such as 'who', 'when', 'where' and 'why' all have significant impact on the quality of the PD. He further suggests that to neglect any of these three dimensions "can significantly diminish the effectiveness of professional development and drastically reduce likelihood of improvement in student learning" (p. 74).

Quality of PD is central to the Guskey and Sparks' model and this in turn leads to the development of teacher knowledge and practice. However, other factors such as the 
climate and culture of the school, supervision and coaching of students, school leadership and organisation, facilities and school infrastructure, and parent knowledge and practices, all have aspects of influence on improved student learning.

The Guskey and Sparks' model identifies the complexity which surrounds teacher PD and the consequences for student learning. This supports the findings of Timperley et al. (2007) where context, content, activities to promote learning, and learning processes are central to measuring its effectiveness and ability to improve student learning.

The similarities between the Kirkpatrick and Guskey and Sparks models are obvious, except Guskey and Sparks' includes a fifth level of evaluation where importance is placed on improved student learning outcomes. This is in line with more recent research which places importance on improved student learning outcomes. (AltonLee, 2003; Hill et al., 2001 ; Timperley et al., 2007). There are other models which enable the evaluation of PD and training and these identify adaptations or modifications to those already mentioned.

The inclusion of the models of evaluation above provides opportunity to consider that whilst Guskey and Sparks' model was designed specifically for an education context, Kirkpatrick's and other models can be adapted to do the same thing. In adapting these models, the literature indicates that a key aspect of evaluating the effectiveness of PD in an educational context is placing a focus on improved student achievement (Meiers \& Ingvarson, 2005), and what evidence might be gathered to demonstrate this. These evaluation models also indicate that whilst improved student achievement is a key aspect of effective PD, a range of other factors are of importance and they need to be considered (planned for) when designing programmes.

\section{Collaboration and Learning Communities}

DuFour (2004) discusses learning communities as effective structures to support teacher learning through well-planned PD. His model for a professional learning community is based on the assumption that teachers need to focus on student 
learning rather than teachers teaching as cited in Hill et al. (2002), Alton-Lee (2003), Timperley et al. (2007) and others. If teachers are to focus on student learning they need to examine what it is that makes the difference. DuFour suggests that teachers need to consider questions such as:

\begin{abstract}
What school characteristics and practices have been most successful in helping our students achieve at higher levels? How could we adopt those characteristics and practices in our own school? What commitments would we have to make to one another to create such a school? What indicators could we monitor to assess our progress? (p. 8)
\end{abstract}

As teachers engage with these questions, the structure of a learning community is created. Further to this starting point, teachers should consider what each student needs to learn, how teachers will know when it is learnt, and most importantly what they will do if students experience difficulty in this learning. DuFour suggests it is this third point which defines a learning community. A learning community structure within a school will place focus on students who are not learning, and have schoolwide strategies to support them. Both students and teachers are supported in this environment which embraces a collaborative culture. Collaborative arrangements can be uncomfortable for some teachers, however, as it is necessary to 'open up' teacher practice in terms of "goals, strategies, materials, pacing, and results" (p. 10). On the other hand, this allows for a situation where all teachers can feel supported by their colleagues. Teachers are therefore likely to move away from working in isolation such that ideas, strategies and resources may be shared and improved upon.

PD for teachers with a focus on establishing a professional learning community as described by DuFour fits well within the models of teacher learning identified in this review, as improved outcomes for students are central to them. Ingvarson (2002) points out that the concept of professional learning communities aligns closely with teacher PD. He discusses building a learning profession from three perspectives, namely principles, strategies, and contexts for professional learning. His analysis of literature identifies four main trends:

- Identifying what teachers need to learn to improve student learning outcomes. The focus here is on the content of the PD being most important in terms of what it is; how students will learn it; how the teacher delivers the content; and how it is evaluated in terms of student learning. 
- Linking teacher learning to student learning. PD programmes often aim to improve student outcomes through teacher development, but this is difficult to measure. Case study method is discussed as one tool to evaluate this, where the context for learning and teacher intentions are recorded along with a description of the lesson, supported by evidence such as student voice and practical outcomes.

- Making evidence from practice the site for professional learning: building a professional community. PD facilitators need to structure the programme to support participants to discuss with each other what they do, how they are doing it, and what issues they may have. Teachers as part of a learning community within and across schools can be a powerful learning environment. Much research supports this view (Bolam, McMahon, Stoll, Thomas \& Wallace, 2005; DuFour, 2004; Timperley et al., 2007).

- Teaching standards as a framework for long-term PD. Here Ingvarson considers the use of teaching standards to structure teachers' learning in an ongoing manner. He cites Garet (2001) who describes professional learning as being more effective if teachers evaluate their learning and are involved with constructing its scope and duration over a longer timeframe.

Ingvarson (2002) discusses building a learning profession where effective teacher learning is supported. He sees the need for a clear link between teacher learning and improved student learning. Timperley et al. (2007) and others also consider this black box and suggest that new learning for teachers is likely to be most effective if it is linked to, and builds upon, their existing conceptual understandings and knowledge. Ingvarson considers "strong and accountable professional communities" (p. 16) as a structure within which this should occur.

A significant report which examines the effects of different characteristics of PD on teachers' learning is that of Garet et al. (2001). This report analyses teachers' experiences of PD from two angles. Firstly, "structural features" such as whether it involves networks and study groups, as opposed to workshops and conferences; the duration in terms of hours and days; and whether teachers work in school or department-based groups. Secondly, "core features" such as teachers' content knowledge; opportunities for examining student work and feedback on teaching 
strategies; and the focus on teacher goals and communicating with other teachers in an ongoing manner. Garet et al. (2001) considered that the literature on effective PD contained lists of characteristics which were effective but that there was little evidence on how this related to improved student outcomes. They developed a Teacher Activity Survey which enabled them to collect data on PD activities from more than 1000 teachers in order to find what best supported teacher learning. The results from analysis of survey data provided opportunity to consider ways to improve PD from the perspective of enhancing student learning:

- Sustained and intensive PD is more likely to have an impact on student learning rather than shorter PD.

- A focus on academic subject matter (content) which gives teachers the opportunity for 'hands-on' active, rather than passive, learning tends to increase their knowledge and skills.

- Collective participation.

To sum up, improved PD occurs if there is a focus on longer duration, collective participation of teachers, content, active learning, and the encouragement of continuing communication between teachers. Collective participation, in terms of teachers working together collaboratively, was seen as having considerable advantages, such as teachers having the opportunity to discuss knowledge, pedagogical issues and problems they face. If the collaborative practice is between teachers within the same school or department, there will be commonality of materials and resources providing opportunity for mutual support and further development of appropriate resources in the context of the new learning which has occurred. An additional advantage may be that teachers who share the same students can discuss individual needs and improvements across classes and age groups.

The findings of Garet et al. (2001) focus on improved teacher practice but do not specifically examine improvements in student outcomes. Perhaps the shorter duration of the Teacher Activity Survey as a data gathering tool is not able to measure such improvement reliably, although the report is based on a rigorous methodology. Their data do identify a requirement for PD to be of longer duration, content specific and 
structured so that teachers can work collaboratively with a focus on student work in order to change teacher practice in a sustainable way.

A number of researchers have identified that teachers' own learning is enhanced when they are working in learning communities that focus on raising student achievement; this additional focus - student achievement - appears to have sharpened the teachers' own critical self-awareness. Timperley and Parr (2004) consider creating a professional learning community where teachers are mutually supportive improves their learning. Annan, Lei and Robinson (2003) examine teacher conversations, described as 'teacher talk' within learning communities where they define the talk as analytical, critical or challenging 'learning talk'. They mention the fact that several pieces of New Zealand research indicate that teachers engaging in aspects of learning talk in the context of learning communities has significantly contributed to improving teacher learning. Stoll and Fink (1996) discuss PD in the context of learning communities where teachers actively working together respond to their changing context and demonstrate a commitment to learning as an ongoing process. Bath (2001) takes this idea further when he promotes the whole school as a community of learners.

\section{Types and Duration of Professional Development}

Hill et al. (2002) discuss the need for PD to be owned by the participants. That is, that "professional development is more likely to bring about change if the programme is inclusive and stakeholders have ownership of the process" (p. 12). They further discuss the fact that PD needs to be more than attending a short course and picking up a few useful strategies. There needs to be deep learning requiring teachers to change the way they think and do things, a modification of practice which can only come about through critical self-reflection and an examination of the values and beliefs which underpin their practice.

Garet et al. (2001) also find that longer duration PD is more likely to lead to teacher change than one-off sessions. Meiers and Ingvarson (2005) take this further and find that longer duration PD linked improved teacher learning to improved student learning. In fact, almost all literature examined supported the view that extended duration PD was more effective. There are two reasons which consistently emerge; 
these are that longer professional learning opportunities allow for teachers to participate and engage more fully in a process of deeper learning where discussion of knowledge and skills, pedagogical strategies and student understandings can take place. Secondly, that multiple learning opportunities over a period of time allow for teachers to try new knowledge, skills and strategies in their classrooms and obtain feedback and analysis of outcomes.

The most traditional type of PD is a workshop where teachers attend, for varying periods of time, outside the classroom and frequently off site. Courses and conferences are other traditional types of PD which typically have experts attend and run sessions for participants. This type of 'traditional' structure is frequently criticised in the literature (Loucks-Horsley, Hewson, Love, \& Stiles, 1998) as being ineffective due to lack of time for teachers to reflect, participate in activities, and absorb sufficient content knowledge to effect teacher change and changes in their classroom practice (Garet et al., 2001). An alternative type of PD is what Garet et al. refer to as 'reform' where coaching and mentoring is the predominant feature. The advantages of this are that it often takes place in the classroom thereby contextualising the learning for the teacher, and that it can more easily be sustained over a longer timeframe. Ingvarson (2002) also acknowledges that there are a number of aspects to the types of PD which are effective. His include duration that is "extended in time rather than once-off; school based rather than course based; collaborative rather than individual; based on teacher identified needs; and when it provides opportunities for one off support, coaching and reflection on practice" (p. 3). Meiers and Ingvarson (2005) found that the type, or design, of PD which places an emphasis on content knowledge, and how students learn it, along with strategies to deliver the content is important in linking teacher learning to student learning. They found this to be the case in all studies of programmes in their research.

\section{Leadership and Facilitation}

The INSTEP research project resulted in the publication of Ki te Aoturoa (Ministry of Education, 2008). It explored international literature and research with a view to developing knowledge and an evidence base about PD facilitator practice and learning. Ki te Aoturoa can be considered to be a complementary publication to 
Teacher Professional Learning and Development: Best Evidence Synthesis Iteration (Timperley et al., 2007). They both promote inquiry as a vital strategy which PD facilitators must engage in and that facilitator practice and learning should be guided by improved student outcomes in the classroom. In an introduction to Ki te Aoturoa, Timperley coins the phrase "chain of influence" (p. 14) which links facilitator learning to facilitator practice, teacher learning to teacher practice, and student learning to improved outcomes. Timperley et al. (2007) previously explored black boxes which occurred between teacher learning and their practice, and also between student learning opportunities and improved outcomes. Ki te Aoturoa adds a third black box, which occurs between PD facilitator learning and their practice. It examines what does or should occur in this black box. The research identifies a theory for the improvement of facilitator learning and practice based on a range of case studies, inquiry, facilitator knowledge and expertise, and literature. Five principles of facilitator professional learning and practice were proposed:

- Facilitator learning and practice lead to improvements in teacher practice and student outcomes. They can make decisions about their learning needs based on teachers' and students' learning needs; they have high expectations for improvement; and student outcomes can include social, emotional, physical, as well as cognitive outcomes.

- Facilitator learning and practice are underpinned by enquiry and research evidence. They examine the values, beliefs and theories that underpin their everyday practice; they engage with explicit theories of learning and practice; and their practice is evidence based.

- Facilitator learning and practice are developed through collaborative relationships. They participate in professional learning communities and are involved in learning relationships with peers.

- Facilitator learning and practice are influenced by, and responsive to, context and culture. They recognise multiple perspectives and evaluate their performance through a range of 'lenses'.

- Facilitator learning and practice provide and build leadership in a range of contexts. They encourage school leaders to maintain cultures of enquiry based on the use of evidence and to lead professional learning. 
These five principles are supported by resources: 'self', where assumptions, values, beliefs and personal theories are drawn upon; 'others', meaning established theories, educational thinking and understandings and Ministry policies, priorities and strategies; and 'artefacts' such as resources, frameworks, assessment tools and evidence from practice.

Ki te Aoturoa (Ministry of Education, 2008) identifies a theory for facilitator improvement which can impact positively on student outcomes. It supports and progresses work done by Timperley et al. (2007) as it is specifically focussed on understanding the connections and tensions between facilitator learning and improved practice and student learning. The impact of this research and findings is that facilitators can and should examine their own practice with a view to improving what they offer to teachers in terms of PD. The focus changes from what teachers are learning to what facilitators need to learn based on teachers' and students' needs.

Timperley et al. (2007) identify attributes of effective PD which improve student outcomes but accept that this is an area of research which is underdeveloped. They specifically note the "weak theory base for professional learning; limited information concerning the qualities of effective providers, including those in the tertiary sector" (p. 228). They identify what effective professional learning looks like but find a lack of evidence about the qualities of effective facilitators. Ki te Aoturoa goes a long way to addressing this gap in the evidence but accepts further research is required to demonstrate the links between facilitator learning and improved student outcomes.

\section{Improved Student Learning}

A significant study which focuses on PD programmes leading to improved student learning is that of Meiers and Ingvarson (2005). This extensive research draws on international literature and identifies best practice within Australian schools which link teacher PD to student learning. A wide range of models was investigated from several perspectives: the design, structure and learning processes used; the impact of the programme on participants' knowledge, teaching strategies and on student learning; and the effect, if any, on teachers' professional community and their participation in collaborative activities within their schools. The findings from this 
report indicate that not only was their 'cross-programme' study effective in capturing the main factors emerging from wide-ranging practice but that opportunities to learn, active learning, follow-up and feedback impacted significantly on teacher knowledge, practice, efficacy and student learning.

Analysis of Meiers and Ingvarson's data indicates that there are a number of essential components which are necessary to be included in PD design if it is to have an impact on student achievement:

- Opportunity for teachers to focus on what students were to learn and how to best support that learning process (subject content).

- A focus on research-based knowledge about student learning of content.

- Opportunities for teachers to examine student work collaboratively and consider what standards students should be at, and what they should be able to do.

- Teachers being able to actively reflect on their practice against what are considered to be high standards for professional practice.

- Teachers having the opportunity to identify and plan for what they needed to learn.

- Time for teachers to trial new approaches to teaching and receive follow-up support and coaching.

- Activities that lead to teachers de-privatising their practice and gaining feedback from colleagues.

Meiers and Ingvarson (2005) consider their study to be similar to that of Garet et al. (2001) in terms of its theoretical underpinning, and certainly there is commonality within the findings such as a content-based, active, collaborative, learning environment for teachers. Meiers and Ingvarson (2005) extend the work of Garet et al. by making the link to improved student learning. They also draw their data from a range of PD programmes whereas Garet et al. draw their data from a wide range of PD activities through a standardised instrument. 


\section{Pedagogical Content Knowledge}

Schulman (1987) introduced the term 'pedagogical content knowledge' when he studied the knowledge base needed by teachers. He defined it as "a special amalgam of content and pedagogy that is uniquely the province of teachers, their own special form of professional understanding." (p. 8). He stated that this was needed rather than just specific subject knowledge. Grossman (1990) took this further by developing a researchbased model based on recent research which had pedagogical content knowledge centrally supported by four other knowledge domains, namely:

- goals for teaching at particular levels.

- knowledge of pupils' understandings and misunderstandings.

- curricular knowledge within a specific subject.

- instructional strategies.

Rohaan (2009) asserts that the concept of pedagogical content knowledge has been the subject of much research and while there is no single conceptual understanding of its nature, all research agrees that there are two essential aspects" understanding of pupils' specific learning difficulties, and knowledge of representations of the subject matter to overcome these difficulties. It should be noted, however, that some researchers are not able to distinguish between pedagogical content knowledge and other knowledge domains such as subject knowledge (Van Driel, Verloop \& De Vos, 1998). Rohaan (2009) cites Mulholland and Wallace (2005) who noted that pedagogical content knowledge can be interpreted in a number of different ways according to the context of the investigation. However, it seems most research in this field builds upon Schulman's definition.

Research into pedagogical content knowledge and its links to teaching and learning are considered valuable because as the process of instruction is examined, more is learned about how teachers make use of subject matter knowledge in terms of effective learning for students. PD design can be informed by this research. Jones and Moreland (2004) examined pedagogical content knowledge in the context of primary technology education and found links between enhanced teacher pedagogical content knowledge and student learning and motivation in technology. Although their research was in a primary school context, they found pedagogical 
content knowledge was one of the most important domains of teacher knowledge. Rohaan (2009, p. 42) considers pedagogical content knowledge as being "one of the most crucial domains of teacher knowledge" and references Grossman (1990), Jones and Moreland (2004), Magnusson et al. (1999), Shulman (1987), and Van Driel et al. (1998) as all supporting this view.

\section{Key Considerations of Effective Professional Development}

Various writers have identified what might be called key principles which underpin effective PD, for example Timperley et al. (2007), Hill et al. (2002), Mitchell and Cubey (2003), Ingvarson (2002), and Starkey et al. (2006). The following table shows a set of key considerations which I have developed based on the overlapping ideas of authors within this review of literature. It also shows the links between these key considerations and the development of the sub-questions of this research.

Table 2.3: Links between key considerations and sub-questions

\begin{tabular}{|c|c|}
\hline Key considerations derived from research literature & $\begin{array}{c}\text { Research } \\
\text { Sub-questions }\end{array}$ \\
\hline $\begin{array}{l}\text { Content of professional learning needs to consider learning theory; subject content } \\
\text { knowledge; pedagogical content knowledge and be linked to teachers' own } \\
\text { classroom practice. }\end{array}$ & $1,2,5$ \\
\hline $\begin{array}{l}\text { Participants of professional learning should be able to 'own' the process by } \\
\text { identifying their learning needs based on their students' learning needs and on } \\
\text { critical self-reflection. }\end{array}$ & 2,3 \\
\hline $\begin{array}{l}\text { New learning makes use of, challenges, and builds upon teachers' existing } \\
\text { knowledge and conceptual understandings, and embraces their aspirations. }\end{array}$ & 1 \\
\hline $\begin{array}{l}\text { Professional development helps teachers to change their practice, beliefs and } \\
\text { understandings. }\end{array}$ & 1,3 \\
\hline $\begin{array}{l}\text { Facilitators need to identify participants' prior knowledge; experience and learning } \\
\text { needs and plan content and activities accordingly. }\end{array}$ & 4,5 \\
\hline $\begin{array}{l}\text { Professional development design should allow for participants to work } \\
\text { collaboratively, sharing learning experiences and participating in constructive peer } \\
\text { feedback. It should also provide opportunity for sharing experiences from within } \\
\text { their own practice. }\end{array}$ & 3,4 \\
\hline $\begin{array}{l}\text { Professional development should be 'hands-on' and active, rather than passive } \\
\text { learning. }\end{array}$ & 3,4 \\
\hline Participants should have the opportunity to evaluate the PD. & 3,4 \\
\hline $\begin{array}{l}\text { The PD is more likely to impact positively on teacher learning and lead to a change } \\
\text { in practice, if it is sustained and intensive, rather than of shorter duration. }\end{array}$ & $1,2,3$ \\
\hline
\end{tabular}




\section{Sub-questions}

$1 \quad$ How can technology teachers best be supported in their development and practice?

2 In what ways do technology teachers view that effective PD contributes to their practice?

3 What forms of PD do technology teachers consider best supports and improves their practice?

4 To what extent does Teacher Professional Development Facilitator (TPDF) practice influence the effectiveness of the PD?

5 What do Heads of Technology Departments regard as most effective in supporting their technology teachers with changing their practice?

\section{Technology in the New Zealand Curriculum}

Technology in the New Zealand Curriculum (Ministry of Education, 1995) was gazetted in 1999 making technology education mandatory for all students from years 1 - 10. Its aim was to develop in students a technological literacy by experiencing technological practice. Three strands: Technological Knowledge and Understanding, Technological Capability, and Technology and Society provided structure to the technology curriculum across a wide range of technological areas. These strands included materials technology, food technology, electronics and control, biotechnology, structures and mechanisms, production and process technology, and information and communications technology. The work produced by students based on technological practice included consideration of the effects of the development and implementation of the technological outcome on people and the wider environment.

The intent of this curriculum differed from previous workshop craft-based prescriptions in that technological outcomes were developed from more of a sociocultural perspective rather than for their intrinsic 'take home' value and quality of craftsmanship. This shift from an emphasis on high levels of craft and design skills, to a more sociocultural approach to the development of technological outcomes required teachers to adopt more of a constructivist learning theory approach to their teaching, as discussed by Harwood and Compton (2007) and move away from a behaviourist-based approach involving drill, repetition and practice of craft skills as the most important aspect of the learning.

Between 2001 and 2003 the Ministry of Education conducted a review of the National Curriculum with the intention of taking stock of all the curriculum essential 
areas and developments which had occurred over the previous decade. The Curriculum Stocktake (Ministry of Education, 2002) aimed to examine the quality of the New Zealand Curriculum; its implementation and effects on student outcomes; and what developments might be needed in the future. The University of Waikato was contracted to facilitate the National Schools Sampling Study which investigated teachers' experiences of implementing the technology curriculum. This study used questionnaires, focus groups and case studies across the entire school sector, and a number of issues emerged. The primary sector was most concerned with curriculum overcrowding as it was responsible for coverage across all curriculum areas. Intermediate school technology teachers' key concern was managing effective assessment, whereas secondary school technology teachers had problems with understanding the curriculum language and intent as well as a lack of confidence in their content knowledge and pedagogical strategies to deliver this revised technology education effectively. The publication of the New Zealand Stocktake Report resulted in the New Zealand Curriculum Marautanga Project being established with the aim of re-developing the curriculum framework and essential learning areas within it.

Technology education went through another shift with the development of the New Zealand Curriculum (Ministry of Education, 2007a) and the technology essential learning area within it. The focus on developing students' technological literacy remained central but three new strands were introduced: Technological Practice; Technological Knowledge; and Nature of Technology. A new approach to the teaching of technological literacy (Compton, 2007) was developed as a result of perceived limitations in students' understandings; this perception related to the emphasis given in many schools to technological practice alone. The three new strands between them provide opportunity for students to develop a broader, deeper and more critical technological literacy than had previously been the case (Compton \& France, 2006; Compton \& Harwood, 2006).

Many technology teachers have had difficulties in establishing technology education in their schools citing a range of reasons including inadequate facilities, timetable constraints and lack of enthusiasm on the part of both teachers and middle and senior management (Jones, Harlow \& Cowie, 2004). However, a significant sector of technology teachers may have felt out of step with the developments described 
above. These teachers might be highly skilled people with technical and trade backgrounds but who have not had the opportunity to be trained to teach technology. It is likely that their skills and knowledge can contribute to effective technology teaching but without knowledge of the new technological literacy they may be limited in teaching technology effectively.

\section{Effective Technology Teaching}

Rohaan (2009) reviewed the available literature on technology education (in a primary setting) and identified six knowledge aspects specific to technology education. Three domains were categorised from these, which, when integrated, may lead to effective technology teaching. The domains were Subject Matter Knowledge, Pedagogical Content Knowledge and Attitude. These are shown in Table 2.4.

Table 2.4: Technology specific teacher knowledge ${ }^{1}$

\begin{tabular}{lll}
\hline Subject Matter Knowledge & \multicolumn{1}{c}{$\begin{array}{c}\text { Pedagogical Content } \\
\text { Knowledge }\end{array}$} & \multicolumn{1}{c}{ Attitude } \\
\hline $\begin{array}{l}\text { Aspect 1: General subject } \\
\text { matter. }\end{array}$ & $\begin{array}{l}\text { Aspect 3: Knowledge of pupils’ } \\
\text { concept of technology and } \\
\text { knowledge of pupils pre and } \\
\text { misconceptions related to } \\
\text { technology. }\end{array}$ & $\begin{array}{l}\text { Aspect 6: Attitude towards } \\
\text { technology and confidence in } \\
\text { teaching technology. }\end{array}$ \\
Aspect 2: Concept of & $\begin{array}{l}\text { Knowledge of pedagogical } \\
\text { approaches and teaching }\end{array}$ \\
& strategies for technology \\
& education. \\
& $\begin{array}{l}\text { Aspect 5: Knowledge about the } \\
\text { nature and purpose of } \\
\text { technology education. }\end{array}$ \\
\hline
\end{tabular}

Compton and Compton are presently conducting research through a series of case studies and are also attempting to identify the features of effective technology teaching. Whilst this work is currently in progress, the researchers have been able to identify the links between Rohaan's categories and aspects, and effective teaching of the three strands of technology in the New Zealand Curriculum (Ministry of Education, 2007a). They have identified 13 aspects of learning for teachers which relate to effective technology teaching. These are outlined in Table 2.5.

\footnotetext{
${ }^{1}$ Adapted from Compton \& Compton, research in progress.
} 
Table 2.5 identifies the key aspects of knowledge which teachers need to have in order to support student learning across all three strands of technology. It seems the key considerations which emerge from the review of literature, and identification of aspects for effective teaching and learning in technology indicate that the development of teacher knowledge necessary may need to be achieved through effective PD.

Table 2.5: Requirements for effective teaching of technology in New Zealand

\begin{tabular}{lcc}
\hline Subject Matter Knowledge & $\begin{array}{c}\text { Pedagogical Content } \\
\text { Knowledge }\end{array}$ & Attitude
\end{tabular}

Aspect 1:

- Knowledge and practices integral to each component of each strand.

- Including:

- Philosophical understanding of technology.

- Philosophical understanding of technological outcomes.

- Conceptual understanding of technological modelling.

- Conceptual understanding of materials and how they enable products to function.

- Conceptual understanding of system components and how they enable systems to function.

- Procedural understanding of brief development.

- Procedural understanding of organisation and resource management development.

- Procedural understanding of developing and evaluating outcomes.

Aspect 2: Knowledge of how topic knowledge relates to domain knowledge.

\begin{abstract}
Aspect 3: Knowledge of the specific nature of progression for each component of technology from level 1 to 8 of the curriculum.

Aspect 4: Knowledge of how the components relate to each other to support overall progression in technology.
\end{abstract}

Aspect 5: Knowledge of the type (surface/deep) strategic processing required to support a shift in learning.

Aspect 6: Knowledge of student misconceptions, and partial understandings related to each component.

Aspect 7: Knowledge of student current level of understanding related to each component.

Aspect 8: Knowledge of student strategic processing capability.

Aspect 9: Knowledge of when to provide situational interest or support personal interest.

Aspect 10: Knowledge of pedagogical approaches and teaching strategies.

Aspect 11: knowledge of what resources best support learning.
Aspect 12: Positive attitude towards technology.

Aspect 13: Positive attitude to technology education (its value and purpose). 


\section{Technology Teacher Professional Development}

Technology teacher PD is seen as the best way to support all technology teachers with their understanding of the major shifts in the subject (Harwood \& Compton 2007). Certainly the 'technical' teachers mentioned above have needed extensive support as they are, in effect, re-training whilst working full time. All technology teachers need professional support, even those most recently trained. The revised curriculum for technology and its full implementation in 2010 (Ministry of Education, 2007b, p. 6) is substantially different from the previous version, and the introduction of standards-based assessment in 2002 has had major implications on how all technology teachers work. The PD offered, however, needs to be accessible and effective if teachers are being expected to put in considerable time and energy on top of their already extensive workloads. If this is not the case, then there is a danger that they may not fully engage with the new learning and, as a consequence, continue to run programmes for students which will not support effective learning and progression, leading to success with technology achievement standards.

There has been a history of PD and resource development in technology education. An early programme which supported the introduction of Technology in the New Zealand Curriculum in 1995 is described by Compton and Jones (1998). The Facilitator Training Programme aimed to train two groups of 15 technology educators, over a two-year period, with a view to their running professional development programmes in schools. The training of the facilitators was seen as effective as were the programmes these people ran in schools; however, whilst their message and facilitation was consistent between them, there was a limit to the number of schools and teachers they were able to work with. Further to this, financial and time constraints meant they could only deliver an introduction to technology education, rather than in-depth and long-term PD.

A Technology Teacher Development Resource Package was developed by the Centre for Science, Mathematics and Technology Education Research within the Ministry of Education in 1997. It included written and video material titled 'Know How'. This material was intended to support teacher understandings of technological practice, technology education and pedagogy. The package was trialled in fourteen schools 
before being released. The material was seen by many teachers as being effective in its purpose. Some of the resources are still used, but a limitation was that the new knowledge it contained needed to be facilitated rather than accessed voluntarily if it was to have an impact on all technology teachers, rather than just those who chose to engage with it. Facilitation opportunities for all technology teachers were limited.

PD which supported teachers gaining new understandings of the 1995 technology curriculum and its seven technological areas was also facilitated by private providers and by School Support Services attached to the colleges of education and some universities. This varied in its effectiveness across the country as the facilitation and content was constructed by advisers with different backgrounds. Certainly in technology, advisers tended to be people with excellent teaching backgrounds but often not with experience of the new 'technological practice' advocated in the curriculum. Many technology teachers felt that some PD delivered to teachers was not of a consistent nature, possibly due to the unfamiliarity many facilitators had with new subject and curriculum knowledge. The introduction of Ministry of Education National Hui, where facilitators had access to leading subject developers and researchers, may have enabled a more consistent message to become the basis for more effective PD.

The next major PD initiative occurred between 2000 and 2004. It supported the introduction of standards-based assessment, in the form of achievement and unit standards from levels $1-3$ and included scholarship. This Ministry-funded initiative was coordinated nationally and drew upon the expertise of subject specialists and advisers as regional facilitators. These people trained other facilitators using a package of resources developed by a national facilitator. Subject facilitators delivered the PD to teachers at 'Jumbo days' whilst schools were closed freeing up time for effective teacher engagement. Teachers working together was a positive aspect of this PD (Hill et al., 2002) but it was prescriptive, due to the fact that facilitators were instructed to closely follow the resource material step by step. A prescriptive approach to PD can be limited (Timperley et al., 2009) as it may not support deeper learning nor deal with everyday practical issues that arise. These PD jumbo days provided opportunity for teachers to engage with the resources and share understandings of the new assessment structures. They could not, however, be 
described as in depth due to the short, one-off timeframe, and they could not take into account the impact on student learning as described by Hill et al. (2002).

In 2005, as a result of poor 2004 scholarship results, a new PD initiative was introduced which built on what had been learned from previous experience (Ferguson, 2008). It was not structured around a one-day workshop but included seminars for senior management and Boards of Trustees, cluster group professional learning, teacher workshops, additional resources, and follow-up evaluation of effectiveness.

The PD, which supported the introduction of achievement standard assessment for senior students, did more than just inform teachers about a new assessment methodology. It provided the opportunity for technology teachers to examine the subject of technology in terms of its theoretical underpinnings, its content, and the associated pedagogy necessary for effective student learning. (Ferguson, 2008). This seems to have provided the opportunity for many teachers to redevelop junior technology programmes (years 9-10) as it became clear that without effective student learning during these years they were unlikely to have the competencies required for success at senior levels.

\section{Summary}

This review has examined a wide range of key literature about PD generally. It has also described relevant literature in the field of technology education although there is less available, possibly due to the changing nature and focus of the subject over the last 15 years. It indicates that while different authors identify a wide range of factors which need to be considered when planning and implementing PD, there are a number of factors which are 'overlapping' and common to many. Identification of these has enabled me to establish a set of key considerations for effective PD as seen in Table 2.3. I have not included a key consideration about the impact of effective PD on student learning despite this being mentioned by a number of authors because it is beyond the scope of this research. Opportunity for further research, including longitudinal study, may be appropriate to unpack this. The key considerations have allowed the primary research question to be examined in terms of developing the sub-questions and interview questions which have formed the basis for data gathering. 


\section{Chapter Three: Methodology}

\section{Introduction}

This chapter outlines the methodology used in this qualitative interpretive study, which examined the ways teacher PD supports and improves technology teacher practice. It explains the research design, how participants were selected, and how data were gathered and analysed.

\section{Research Aim}

The research aimed to discover how PD for technology teachers who work in a secondary setting in New Zealand can support and improve their classroom practice. It was anticipated that a better understanding of what was effective for teachers in this context will not only support them, but will also support and improve my practice as a PD facilitator, and that of others working in the field of technology education.

\section{Research Question}

The overarching research question I sought to answer through this research was:

From the perspective of technology heads of department and technology teachers, in what ways does teacher professional development support and improve technology teacher practice?

The sub-questions below were constructed in order to facilitate analysis of the primary research question already stated:

- How can technology teachers best be supported in their development and practice?

- In what ways do technology teachers view that effective professional development contributes to their practice?

- What forms of professional development do technology teachers consider best supports and improves their practice?

- To what extent does teacher professional development facilitator (TPDF) practice influence the effectiveness of the professional development?

- What do heads of technology departments regard as most effective in supporting their technology teachers with changing their practice? 
In order for the primary research question of this thesis to be examined and for the opportunity to gather rich data, it was broken down into five sub-questions. The review of literature enabled me to develop a set of key considerations of effective PD, based on what was most common across authors. This set of key considerations allowed for identification of the themes: support; classroom practice; types of PD; facilitation; and leadership. It also enabled the sub-questions to be developed. Table 2.3 outlines these key considerations of effective PD and the links with themes and sub-questions. The sub-questions were broken down further into individual interview questions for heads of department and technology teachers. These can be seen in Table 3.1 below

Table 3.1: Research questions

\begin{tabular}{|c|c|c|c|}
\hline Themes & Research Sub-questions & $\begin{array}{l}\text { Heads of Department } \\
\text { Interview Questions }\end{array}$ & $\begin{array}{c}\text { Teacher Interview } \\
\text { Questions }\end{array}$ \\
\hline Support & $\begin{array}{l}\text { How can technology } \\
\text { teachers best be supported } \\
\text { in their development and } \\
\text { practice? }\end{array}$ & $\begin{array}{l}\text { Can you tell me about } \\
\text { your PD experiences? } \\
\text { In what ways has this PD } \\
\text { supported your } \\
\text { development and practice? } \\
\text { How has PD supported } \\
\text { you as an HoD? }\end{array}$ & $\begin{array}{l}\text { Can you tell me about } \\
\text { your PD experiences? } \\
\text { In what ways has this PD } \\
\text { supported your } \\
\text { development and practice? }\end{array}$ \\
\hline $\begin{array}{l}\text { Teacher } \\
\text { Practice }\end{array}$ & $\begin{array}{l}\text { In what ways do } \\
\text { technology teachers view } \\
\text { that effective professional } \\
\text { development contributes to } \\
\text { their practice? }\end{array}$ & $\begin{array}{l}\text { Can you tell me about PD } \\
\text { that you believe has } \\
\text { impacted upon your } \\
\text { classroom practice or the } \\
\text { classroom practice of } \\
\text { technology teachers? }\end{array}$ & $\begin{array}{l}\text { Can you tell me about PD } \\
\text { that you believe has } \\
\text { impacted upon your } \\
\text { classroom practice? } \\
\text { Can you give me some } \\
\text { examples from your } \\
\text { practice? }\end{array}$ \\
\hline $\begin{array}{l}\text { Form/Type/ } \\
\text { Style of PD }\end{array}$ & $\begin{array}{l}\text { What forms of } \\
\text { professional development } \\
\text { do technology teachers } \\
\text { consider best supports } \\
\text { their practice? }\end{array}$ & $\begin{array}{l}\text { Can you tell me about the } \\
\text { types of PD you have } \\
\text { experienced? } \\
\text { Was any particular type or } \\
\text { style of PD more effective } \\
\text { than others? }\end{array}$ & $\begin{array}{l}\text { Can you tell me about the } \\
\text { types of PD you have } \\
\text { experienced? } \\
\text { Was any particular type or } \\
\text { style of PD more effective } \\
\text { than others? }\end{array}$ \\
\hline Facilitation & $\begin{array}{l}\text { To what extent does } \\
\text { professional development } \\
\text { facilitator practice } \\
\text { influence the effectiveness } \\
\text { of the PD }\end{array}$ & $\begin{array}{l}\text { Can you describe } \\
\text { strategies employed by } \\
\text { your facilitators? } \\
\text { In what ways were these } \\
\text { helpful? Or not? }\end{array}$ & $\begin{array}{l}\text { Can you tell me about the } \\
\text { practice of different } \\
\text { facilitators you have } \\
\text { worked with? }\end{array}$ \\
\hline Leadership & $\begin{array}{l}\text { What do heads of } \\
\text { technology departments } \\
\text { regard as most effective in } \\
\text { supporting their } \\
\text { technology teachers with } \\
\text { changing their practice? }\end{array}$ & $\begin{array}{l}\text { Can you tell me about how } \\
\text { PD can best support the } \\
\text { teachers in your } \\
\text { department? } \\
\text { What role do you think } \\
\text { technology leaders have in } \\
\text { PD? }\end{array}$ & $\begin{array}{l}\text { What role do you think } \\
\text { HoDs need to take with } \\
\text { respect to PD in their } \\
\text { departments? }\end{array}$ \\
\hline
\end{tabular}




\section{Qualitative Research}

This research made use of qualitative methods. Denzin and Lincoln (2005) define qualitative research as:

a situated activity that locates the observer in the world. It consists of a set of interpretive material practices that make the world visible...it involves an interpretive, naturalistic approach to the world. This means that qualitative researchers study things in their natural settings, attempting to make sense of, or interpret, phenomena in terms of the meanings people bring to them. (p. 3)

Interviewing teachers is one of a number of methods of gathering qualitative data, which can also include observation, and examination of artefacts and documentation (Denzin \& Lincoln, 2005). Interviewing 10 teachers enabled a rich set of data to be gathered in terms of teacher voice within a natural and authentic setting. A qualitative interpretive approach enabled me to explore the positive and negative aspects of PD which teachers had experienced from their own point of view without bias on my part. It also enabled me to gain a balanced understanding of the wide variety of factors which teachers considered when they evaluated the effectiveness of their PD experiences.

My key research question required investigation into how PD can support and improve technology teacher practice. Yin (2003) discusses this and points out that the way in which a researcher defines the problem and constructs the questions determines the research design. He considers research questions which ask 'how' and 'why' are "likely to favour the use of case studies, experiments or histories" (p. 6). He views these as being suitable research methods because they help the researcher understand and explain what is being studied, based on teachers' own experiences, over a period of time. 'How' and 'why' questions underpin this research using a case study approach.

\section{Research Design}

Ten technology teachers/heads of departments from secondary schools within one region were interviewed. Interviews were held with each teacher individually to allow for their subjective experiences to be examined within a constructivist paradigm. Content analysis (Berg, 2004) was used to analyse the data. This enabled the data to be sorted into similar themes across the participants, thereby establishing 
the content units. Further explanation of this is provided in the Sorting and Categorising section of this chapter.

Interviews were the only form of data gathered because the number of teachers interviewed, and the wide range of questions asked of teachers provided a large amount of rich data to inform this research and adequately answer the primary research question.

\section{Constructivist Paradigm}

A constructivist paradigm, an epistemology which argues that people create knowledge and meaning by reflecting on their past experiences and prior knowledge, will allow an understanding of teachers' attitudes and beliefs about their experiences of PD. Neuman (1994) considers three main theoretical groupings which impact on research methodology, namely positivist, critical, and, relevant to this research methodology, interpretivist. It is this third approach described as "the systematic analysis of socially meaningful action through the direct, detailed observation of people in natural settings in order to arrive at understandings and interpretations of how people create and maintain their social worlds" (Neuman, 1994, p. 68) which Mutch (2005) describes as "related to theories of symbolic interactionism, phenomenology, social constructionism, and hermeneutics" (p. 64). Case study is a typical methodology for a constructivist theoretical approach because it allows the researcher to construct meaning and understanding based on interview responses from teachers 'in their natural settings', that is, as participants in PD. It allows for the construction of new knowledge based on what is already known. The reflections of teachers enabled the researcher to consider the main research question from both the teacher's point of view and that of their head of department (HOD). The representation of the teacher's voice and the identification of the ways that teachers consider PD can support and improve their practice was central to this enquiry.

\section{Selection of Participants}

Teachers were selected from secondary schools which were within the proximity of the researcher's city and were known by the researcher. Initial contact was made by phone call requesting their willingness to participate. Positive responses were 
followed up by phoning the principal requesting permission, and if agreeable forwarding an information sheet and formal request to participate to both teacher and principal by mail. The information sheet described this research and its purpose as shown in Appendix 2.

\section{Participants}

The participants for this research were selected using purposive sampling in line with case study research (Yin, 2003). Teachers and heads of technology were interviewed independently of each other. Purposive sampling was used to take account of teachers, heads of department, and length of teaching experience. As can be seen in Table 3.1, slightly different questions were asked of teachers and heads of departments. There was a question about leadership specific to heads of department in order to get their views. Teachers were selected who were at varying stages of their careers, for example, teachers who had been practising for 0-5 years, 6-10 years, 11+ years, and heads of departments. Gathering data from both heads of technology and technology teachers with different levels of experience was considered important to get a range of responses. By organising information in this way, themes or patterns in the data may have emerged which are unique to the level of experience or responsibility that the teacher has in the school.

The details of participants and their schools are outlined in Table 3.2.

Table 3.2: Participants details and experience

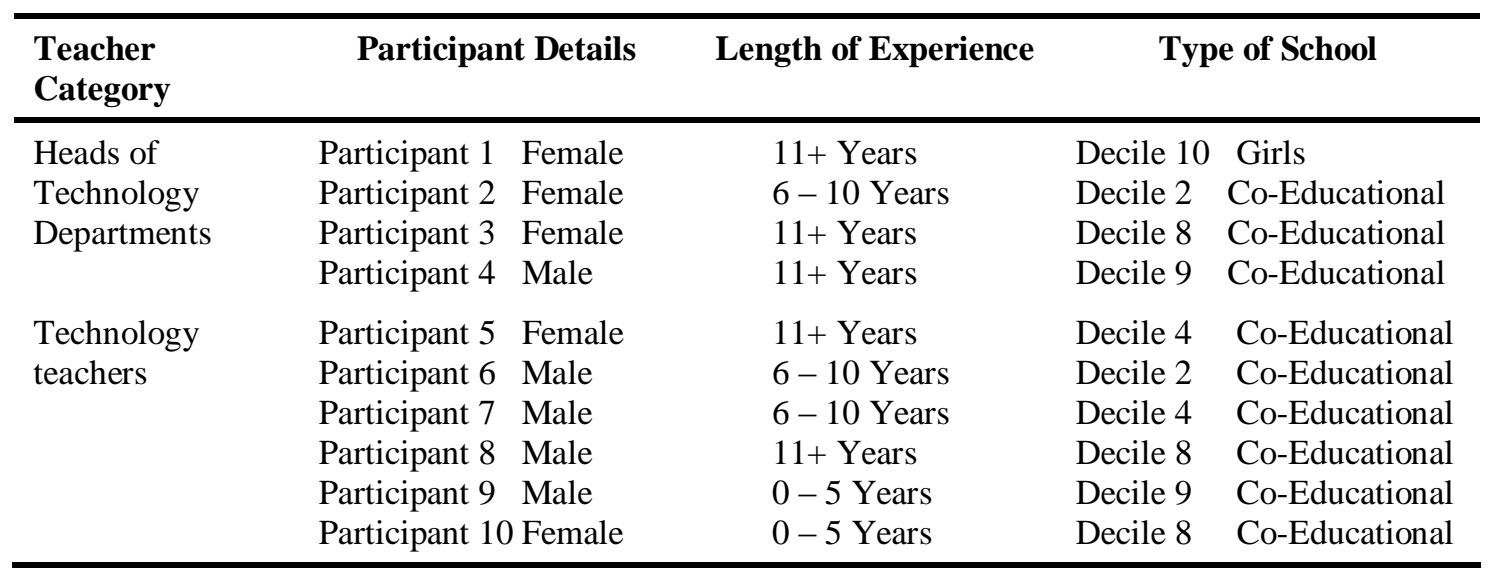




\section{Ethical Considerations}

Ethical protocols were adhered to in line with Victoria University of Wellington research policy which ensured that the identity and interests of the research participants was protected at all times.

\section{Informed Consent}

Consent for the research was gained through the use of consent forms which required a tick to each paragraph and a signature as shown in Appendix 3. This was forwarded to participants and principals along with a detailed information sheet. Separate information sheets were developed for both teacher and principal. All participants were given the right to accept or decline involvement in this research and were also informed that they could withdraw at any time.

\section{Confidentiality and Anonymity}

Confidentiality and anonymity were maintained by using codes for all participants (see Table 3.3). All information gathered, including names of schools, principals and teachers was kept confidential. A transcriber confidentiality form was also developed requiring a signature. All participants were assured that they would remain anonymous and no mention of the names of their schools would appear anywhere in the research.

Participants were informed about the security and availability of documentation and audio recordings and the right of participants to monitor their use. All data and recordings were stored in a locked cabinet. Participants were also informed of their right to receive a copy of this thesis on completion and reassured that their details would remain confidential.

\section{Data Collection Procedures}

Data were gathered from teacher participants by means of audio recorded qualitative interviews which were arranged and took place outside of normal school times to avoid disruption to everyday teaching and related responsibilities. Each was approximately 25 - 30 minutes in length. Although interviews might normally take longer, it became evident that answers to several questions often emerged together, shortening the time required. The interviews were semi-structured and conducted one 
to one. Mutch (2005) describes this approach as enabling the researcher to get an indepth understanding of experiences and views from the perspective of the participant. Teachers were able to tell their own PD stories as part of the interview. The nature of semi-structured interviews allows for discussion and further questions to be used as appropriate based on the interview conversation.

Immediately prior to the interview teachers were reminded of the purpose of the research and interview, and that the conversation would be digitally recorded, even though this was in the information sheet they received at the outset. Teachers were sent a copy of the interview framework at least one week prior to the interview in order for them to consider carefully their responses. Following the interviews, digital recordings were downloaded to the computer and copied to CDR disks for security purposes. Electronic WMV files were emailed to a professional transcriber where they were converted to text and emailed back. The transcriber was requested to sign a confidentiality agreement.

\section{Data Analysis: Sorting and Categorisation}

The audio recorded interviews were transcribed in full and analysed using content analysis.

\section{Content Analysis}

Content analysis involves categorisation of themes present in the interview data. It works by drawing out the themes inductively rather than by imposing them upon the data. Content analysis, first introduced by Berelson in 1952, allows for the qualitative data to be grouped according to the frequency with which the data were mentioned. This produced a quantitative structure of content units which can be analysed to make meaning of a wide range of teacher experiences and opinions. The data are quantified, yet they still have their qualitative value of description. Berg (2004) writes that both the qualitative and quantitative aspects of the teacher voice may be a focus through content analysis. Not only were themes identified by frequency, commonalities and strengths in the data could be noted.

The interview data gathered for this research were qualitative in nature, that is, teachers' views and experiences. By using content analysis, the qualitative data have 
been grouped according to the frequency with which they were mentioned. Content analysis in this work refers to applying an inductive coding allowing the major themes to emerge from the data (Berg, 2004). This process endeavoured to eliminate the tendency for partial or biased analysis which could occur if only selected content which fitted with preconceived notions about the PD was used.

Each transcript was coded into content units by the researcher and a paraphrase was written from the text in order to describe the content. These content units were then sorted across all the transcripts into common themes; this process was repeated twice until categorisation was complete and a coding scheme arrived at. As the content units were itemised, the data could be further organised according to the frequency with which similar themes occurred.

This approach was selected as the researcher felt it was important to represent the teachers' voice authentically rather than impose a set of categories on the data. Although teacher PD is well researched and the interview questions were based on major themes arising from the literature, technology teachers have not informed part of this research. It was important that the 'voice' of technology teachers was carried through the coding and analysis.

Table 3.3 shows an example of content units which have been manually edited from full transcripts, along with the code. The paraphrases were developed by the researcher with text taken directly from the transcript. This process enabled content units with a common theme to be grouped together and therefore ranked in numerical order. The code represents the teacher's name and number of the content unit within this teacher's transcription. Teacher name can be identified by the researcher as being from one of four groups: teachers with 0 to 5 years experience; $6-10$ years experience; 11+ years experience; and heads of department. Example Transcript is teacher voice transcribed. Paraphrase, developed by the researcher, to each content unit enables common paraphrases to be grouped together and ranked numerically. 
Table 3.3: Sample transcript and coding

\begin{tabular}{|c|c|c|}
\hline $\begin{array}{l}\text { Person and } \\
\text { Initial Code }\end{array}$ & Example Transcript & Paraphrase \\
\hline P.40 & $\begin{array}{l}\text { Perhaps negotiating with senior management for } \\
\text { you to get time off to attend professional } \\
\text { development. }\end{array}$ & HOD to organise PD \\
\hline B. 42 & $\begin{array}{l}\text { Mostly I do one on one PD with teachers because I } \\
\text { might have an English teacher who's asked to take } \\
\text { a yr } 7 \text { technology project and they say they don't } \\
\text { know how to teach it. }\end{array}$ & $\begin{array}{l}\text { HOD does } 1 \text { on } 1 \text { PD with } \\
\text { teachers when necessary. }\end{array}$ \\
\hline JM.57 & $\begin{array}{l}\text { They (HODs) need to recognise that professional } \\
\text { development is really important and that teachers } \\
\text { should have some say, some input into where } \\
\text { they'd like to aim, where they'd like to go. }\end{array}$ & $\begin{array}{l}\text { HODs need to let teachers } \\
\text { decide on PD opportunities }\end{array}$ \\
\hline P.37 & $\begin{array}{l}\text { You've got to make sure that people (teachers) new } \\
\text { to the job know what they are doing. And that's } \\
\text { what I'm trying to do with our new teacher, show } \\
\text { her exactly what she needs to do. }\end{array}$ & $\begin{array}{l}\text { HOD needs to support new } \\
\text { teachers. }\end{array}$ \\
\hline K. 37 & $\begin{array}{l}\text { So, it's quite good when I can use that professional } \\
\text { development to fall back on, and also the } \\
\text { department minutes to remind people where we've } \\
\text { decided to go as a department. }\end{array}$ & $\begin{array}{l}\text { HOD can use PD to drive } \\
\text { change in the department. }\end{array}$ \\
\hline K 50 & $\begin{array}{l}\text { I think they (HODs) have a big role to play in } \\
\text { professional development, I fully believe leading } \\
\text { by example. If you expect people to do this you } \\
\text { need to have done it. }\end{array}$ & $\begin{array}{l}\text { HODs need to lead by } \\
\text { example. }\end{array}$ \\
\hline RB. 52 & $\begin{array}{l}\text { If a member of the department says "I need some } \\
\text { professional development in this, and I have } \\
\text { identified a certain course", then the HOD should } \\
\text { get behind it because the more training your staff } \\
\text { get the better they will be. }\end{array}$ & $\begin{array}{l}\text { HOD should organise PD } \\
\text { based on teacher requests. }\end{array}$ \\
\hline
\end{tabular}

Categories which are used by researchers in a content analysis can be determined deductively, inductively or by a combination of both (Strauss, 1987). An inductive approach allows researchers to link these categories to the data from which they derive (Berg, 2004) whereas in a deductive approach researchers use some categorical scheme based on a theoretical perspective. What is important here is that categories are grounded in the data from which they emerge (Denzin, 1978; Glaser \& Strauss, 1967).

The categorisation of the data moved through three levels of generalisation beginning at level 1 and moving to levels 2 and 3. Similarity of content and frequency at which they occurred in the data enabled sorting to take place. Level 1 involved identifying themes or content units within the transcriptions. These were given a code based on the teachers' initial and the numerical order of the content unit within that 
transcription. A paraphrase was attached to each content unit which came directly from the content in the transcribed interviews. Table 3.3 shows the level coding. The number of times a content unit occurred across all 10 transcriptions was recorded. The level 2 sorting involved grouping the paraphrases according to similarity across all transcripts. This resulted in the identification of similar themes across transcriptions that could be grouped. The frequency of each theme was recorded. Codes (labels) were then assigned to these categories. Thirty seven such categories were identified. This further generalisation in the data resulted in major themes or categories, the content units which made up these themes and the frequency at which they occurred. A synthesis of these categories is shown in Table 4.2. This was based on degree of similarity or possible overlap of content and provided opportunity for further analysis of the data.

\section{Frequency}

The requirement of quantification, common to all definitions of content analysis, is of primary importance and is based on the extent to which the analytic categories appear in the content. In this study the content units were coded, sorted and the frequency with which they occur is recorded. This could be within the same, or across all of the transcriptions. By recording the frequency of the concept in the text, the importance of it may be established. Berg (2004) suggests that when researchers demonstrate the appearance of an observation in a large proportion of the data being studied their arguments are more convincing.

The findings of this research are based on the frequency at which similar content units occur within the transcripts. This is illustrated in the following table which provides a breakdown for two categories. Under each category heading the content units are presented; the frequency for each unit is shown along with the percentage for the overall frequency associated with each category. 
Table 3.4: Frequency table (part) showing content units, categories and frequency

\begin{tabular}{|c|c|c|c|c|}
\hline Rank & Categories with content units & Frequency & $\%$ & Cumulative \% \\
\hline \multirow[t]{18}{*}{1} & Teachers sharing practice & 45 & 9.6 & 9.6 \\
\hline & Sharing ideas with other teachers works well & 18 & & \\
\hline & $\begin{array}{l}\text { Teachers attend PD and bring back information to } \\
\text { share with the department. }\end{array}$ & 5 & & \\
\hline & $\begin{array}{l}\text { Teachers share resources and improve on them } \\
\text { through the PD }\end{array}$ & 2 & & \\
\hline & Contact with other teachers and sharing ideas & 2 & & \\
\hline & Sharing examples of student work & 3 & & \\
\hline & Sharing resources works well & 2 & & \\
\hline & Working on schemes together & 2 & & \\
\hline & All participants need to bring work to share & 2 & & \\
\hline & Sharing practice and getting suggestions from others & 1 & & \\
\hline & Cooperative learning and sharing & 1 & & \\
\hline & Teachers share PD opportunities according to need & 1 & & \\
\hline & Only a small group of people share and attend & 1 & & \\
\hline & Interactive PD is best where we share ideas & 1 & & \\
\hline & Sharing strategies with other HODs & 1 & & \\
\hline & Sharing practice in school & 1 & & \\
\hline & Teachers sharing experiences & 1 & & \\
\hline & Sharing practice helps create a community & 1 & & \\
\hline \multirow[t]{24}{*}{2} & Content of PD & 41 & 8.7 & $\overline{18.3}$ \\
\hline & Domain knowledge rather than pedagogy & 6 & & \\
\hline & Need subject specific PD & 5 & & \\
\hline & PD on language writing & 4 & & \\
\hline & Moderator training great PD & 3 & & \\
\hline & Subject association & 3 & & \\
\hline & PD needs to be relevant and open to understanding & 2 & & \\
\hline & Practical ICT PD needed ...skills based. & 2 & & \\
\hline & Relevant up to date information at PD is important & 1 & & \\
\hline & $\begin{array}{l}\text { Combination of PD needed, senior assessment and } \\
\text { skills development }\end{array}$ & 1 & & \\
\hline & $\begin{array}{l}\text { PD style 'what's on top, what's not' often solves } \\
\text { problems }\end{array}$ & 1 & & \\
\hline & Cross-curricular approach to PD & 1 & & \\
\hline & PD supported programme planning & 1 & & \\
\hline & $\begin{array}{l}\text { Teacher practice is supported by PD at College or } \\
\text { University }\end{array}$ & 1 & & \\
\hline & $\begin{array}{l}\text { PD needs to differ according to how long you have } \\
\text { been teaching }\end{array}$ & 1 & & \\
\hline & $\begin{array}{l}\text { PD experiences other than subject specific } \\
\text { technology is also important }\end{array}$ & 1 & & \\
\hline & PD on NZC 2007 needed & 1 & & \\
\hline & PD on classroom management skills needed & 1 & & \\
\hline & Need support to re write some programmes & 1 & & \\
\hline & HODs need PD to support their teachers & 1 & & \\
\hline & $\begin{array}{l}\text { I never had PD in technology before the recent in } \\
\text { depth work }\end{array}$ & 1 & & \\
\hline & Deadlines for ERO & 1 & & \\
\hline & $\begin{array}{l}\text { PD where teachers go away with information to } \\
\text { make life easier }\end{array}$ & 1 & & \\
\hline & $\begin{array}{l}\text { Need more PD on NCEA assessment practice and } \\
\text { senior assessment generally }\end{array}$ & 1 & & \\
\hline
\end{tabular}




\section{Validity and Reliability}

Both normative and interpretive research approaches need to consider the notion of fitness for purpose (Hall, 2007). The research design may be considered fit for purpose if it is appropriate for answering questions. In the case of this interpretive research the design did allow research questions to be answered.

Trustworthiness also needs to be considered. A number of factors constitute trustworthiness in research; they include what Hall (2007) "describes as the coherence of overall design in relation to the research questions; appropriate methods, strategies and data analysis techniques; clarity and detail about the research process; evidence of reasonable interpretations and clarity of reporting” (p. 5).

There are two key concepts of validity, those of credibility and transferability. Credibility relates to plausibility of the results and requires detailed and accurate description of the research process and data for it to be deemed credible. Examples of this might be attention to detail; interpretations based firmly on what the data says; appropriate use of triangulation; peer feedback on processes and interpretations; looking for evidence which challenges interpretations; and checking for accuracy of fact and meaning with research respondents. This research has made use of both peer debriefing, where coding of two transcripts was initially undertaken with my supervisor to ensure consistency, and investigator triangulation with my second supervisor. Transferability within this research has been addressed in terms of rich/thick description providing opportunity for readers to decide if any of the results are of use in their own individual contexts.

According to Hall (2007), "reliability focuses on the notion of accuracy. This covers attention to detail throughout all stages of the research (e.g., observations, measurements, interpretations, and reporting), and applies to quantitative measurements and analysis as well as qualitative observations, recordings and interpretations" (p. 6). Checking for consistency within the coding of the qualitative data and auditing the thick/rich data with supervisory peers have supported the accuracy and therefore reliability of this research. Triangulation within the data, for example, data from heads of department and teachers with different levels of 
experience, together with triangulation within the literature, has further supported the notion of the reliability of this research.

\section{Limitations}

The scope of this Masters research does not attempt to cover the links between student achievement and teacher PD. Much of the literature examined, for example, Hill et al. (2002), Timperley et al. (2007), agrees that effective PD needs to be linked to improved student learning, and that there is a black box around this area. Students and their work may need to be identified to examine this. Longitudinal research may be required as part of understanding these links, providing opportunity for later $\mathrm{PhD}$ research. A further limitation may be making use of interviews as the only form of data gathering; also that interviews with 10 teachers is a small sample size, and that these interviews were time bound. A broader study might have gathered more data after participants had experienced PD informed by initial findings. Again, this may be an opportunity for further research in the future.

\section{Summary}

This research sought to find out in what ways teacher PD can support and improve technology teacher practice. In order to achieve this, the research question was broken down into five sub-questions based on major themes which emerged from a thorough review of literature. A qualitative case study design was used and data were gathered by interviewing 10 technology teachers including technology department heads. Interviews were semi-structured, allowing for flexibility within the interview structure such that richer data could be gathered in terms of teacher 'voice', and for the researcher to gain an in-depth understanding of technology teachers' views and experiences of PD.

The interview data were transcribed and sorted using inductive content analysis which enabled the data to be analysed and categorised. It also enabled data to be viewed quantitatively. The frequency table contains 469 content units within 37 categories and is shown in Appendix 1. The frequency with which the content units occurred along with the percentage and cumulative percentages are also displayed in order that the importance of aspects of the data could be considered. 
The following chapter describes the findings of this research by considering the content units and their rank order of importance. It also synthesises the categories in order to facilitate links to the reviewed literature. 


\section{Chapter Four: Findings}

\section{Introduction}

This chapter contains the findings of this research. It includes Table 4.1 which shows the categories into which the content units are placed, in rank order; the number of content units in each category (frequency); and the overall percentage of each category across all the data.

A description of the main categories is included which has been informed by consideration of the content units which make up each category and the frequency with which they occur. A further synthesis of the categories is also included, allowing them to be grouped, based on degree of similarity or possible overlap in their content. This can be seen in Table 4.2.

\section{Summary of classification of responses into categories}

As noted in Chapter Three, the interview data were classified into 37 categories. Each category comprised content units of information that the researcher, with the supervisor acting as a critical friend, believed represented teachers' views as described by them within the transcribed interview data. Content analysis allowed for inductive coding of data and categories to be established.

Table 4.1 lists the categories in terms of frequency and percentage of units that were coded under each category. Categories were arranged in rank order based on the frequency of their content units. As can be seen from Table 4.1, over $55 \%$ of all content units are within the top nine categories indicating the importance teachers who were interviewed, placed on these categories. 
Table 4.1: Rank order, categories, frequency and percentage of total

\begin{tabular}{|c|c|c|c|}
\hline Rank & Category & Frequency & $\%$ \\
\hline 1 & Teachers sharing practice & 45 & 9.6 \\
\hline 2 & Content of PD & 41 & 8.7 \\
\hline 3 & HOD Role & 39 & 8.3 \\
\hline 4 & Teachers working together & 28 & 6.0 \\
\hline 5 & What works for me as a result of PD & 25 & 5.3 \\
\hline 6 & PD types & 23 & 4.9 \\
\hline 7 & NZQA/NCEA PD & 20 & 4.3 \\
\hline 8 & PD facilitator practice & 19 & 4.1 \\
\hline 9 & Student work as exemplars & 18 & 3.8 \\
\hline 10 & Delivery & 13 & 2.8 \\
\hline 11 & Teacher change & 13 & 2.8 \\
\hline 12 & 1 on $1 \mathrm{PD}$ with facilitator & 12 & 2.6 \\
\hline 13 & Some PD is ineffective & 12 & 2.6 \\
\hline 14 & Technology is a difficult learning area for teachers & 11 & 2.3 \\
\hline 15 & Time is needed for PD & 11 & 2.3 \\
\hline 16 & Problems with PD & 10 & 2.1 \\
\hline 17 & Follow-up to PD is required & 10 & 2.1 \\
\hline 18 & Improved student outcomes & 9 & 2.1 \\
\hline 19 & School wide PD & 9 & 1.9 \\
\hline 20 & There are problems with some resources & 9 & 1.9 \\
\hline 21 & Visitors as a resource & 7 & 1.5 \\
\hline 22 & Changes in school/classroom & 7 & 1.5 \\
\hline 23 & Beacon Practice problems & 7 & 1.5 \\
\hline 24 & Learning styles/ types of learners & 7 & 1.5 \\
\hline 25 & Curriculum 2007 support is needed & 6 & 1.3 \\
\hline 26 & Technology teachers not trained in technology & 5 & 1.1 \\
\hline 27 & Teachers' attitudes & 5 & 1.1 \\
\hline 28 & Beacon practice successes & 5 & 1.1 \\
\hline 29 & Cluster meetings are important & 5 & 1.1 \\
\hline 30 & Flexible & 5 & 1.1 \\
\hline 31 & PD opportunities in the past & 5 & 1.1 \\
\hline 32 & Reading is important & 5 & 1.1 \\
\hline 33 & Limited PD opportunities & 5 & 1.1 \\
\hline 34 & School issues around PD & 4 & 0.9 \\
\hline 35 & Funding needed. & 4 & 0.9 \\
\hline 36 & Greater understanding of teaching practice in technology & 4 & 0.9 \\
\hline 37 & PD resources & 4 & 0.9 \\
\hline
\end{tabular}




\section{Description of the main categories}

This section picks out the major categories for further description. Categories that achieved at least $3 \%$ of the total are described. Although this is an arbitrary choice, the view of the researcher is that categories smaller than this do not warrant particular discussion.

\section{Analysis of data and research findings}

Analysis of all the interview data showed that there were a total of 469 content units grouped into 37 categories. There appeared to be no discernable difference between the attitudes of teachers in the groups of teachers with different levels of experience, that is, teachers who have 0-5 years' teaching experience, 6-10 years, and 11+ years' experience. Further to this, there was little difference between the needs of these groups and the HOD group. Content units showed that teachers had high expectations of the role of their HOD in providing PD opportunities and supporting their teachers to participate. HODs were aware of their responsibilities to teachers in their departments and content units indicate that they provided PD for them on occasions. However, teachers and HODs recognised that all teachers needed to update their knowledge due to the significant changes of curriculum and assessment. Several content units mentioned the facilitator, whether they were the HOD or an external facilitator, needed to have relevant up-to-date information.

\section{Teachers sharing practice}

This was the largest group to emerge from the data analysis with 45 content units representing $9.6 \%$ of the total. Eighteen of the 45 content units stated that teachers sharing their ideas and resources with each other at PD meetings worked well for them. The ideas referred to in the interviews were contexts for teaching technology, that is starting points for students' technological practice where students investigate and develop a specific brief to work with; strategies of how to engage students in the three strands of technological practice, knowledge and nature where teachers explore different ways of delivering the focused learning required; and classroom management strategies which encourage active participation and engagement of students in a technology education environment. The resources were such things as examples of successful units of work which engaged students well and allowed for high quality technological outcomes. 
Other aspects of sharing concerned domain knowledge, where teachers needed to work within unfamiliar technological areas and required practical skills and knowledge in order to support their students. Increasingly, units of work in effective technology programmes provide opportunity for students to work across a wide range of technological areas drawing on an increasingly wide range of practical and intellectual skills. Teachers often need to respond to this challenge.

The sharing described by teachers also involved participants bringing information gained and resources developed, through contact with the facilitators and with other teachers, back from PD experiences, and working with these with colleagues and students in their schools. Due to time constraints it is often the case that only one or two members of a technology department can attend the PD simultaneously. Teachers sharing what they have gained with their colleagues is an effective way to overcome this.

Teachers sharing resources that they find effective and developing new ones is a common aspect of PD. This provides the opportunity to critique and review what works well and what does not. Further to this, PD courses provide opportunity for teachers to share and discuss student outcomes in terms of actual student work. Content units stating that seeing actual student work is highly beneficial to teachers is common throughout the data.

\section{Content of PD}

The second category with 41 content units representing $8.7 \%$ of all content units identified that teachers wanted PD which supported advancing their domain knowledge, skills and the ability to develop successful programmes of learning for their students, rather than pedagogical knowledge. Domain knowledge has changed significantly within technology education due to the development of the subject from its craft and practical skill-based origins, through the design technology phase to its present structure. Teachers reported that the PD needed to be relevant, progressive and frequent in order to support them effectively with the changes occurring in the technology learning area. Teachers' views of what was relevant content, varied. Over $30 \%$ of content units in this category referred to a need for subject specific domain knowledge about technology and the development of student technological literacy. 
This may be due to the changes in the subject already mentioned. Other content units referred to assessment, especially at senior NCEA level, programme planning and development, classroom management within a workshop environment, and the New Zealand Curriculum (Ministry of Education, 2007a). There was also reference to skills development needed including ICT.

Several content units related to PD information needing to be relevant, up to date and targeted to teachers' specific needs, particularly identifying that teachers' needs varied according to how long they have been teaching and their experience. Some experienced teachers had participated in national moderator training facilitated by NZQA. These teachers considered this subject specific training on senior assessment to be a good model.

PD content needing to be relevant to specific teacher needs, up to date, in-depth, and open to understanding comes through strongly in this category.

\section{HOD role}

There were 39 content units, $8.3 \%$ of the total, relating to the role of the HOD in PD. The data here came from interviews with both HODs and technology teachers.

There were two content units in this category with the highest and equal numbers. One was that both teachers and HODs considered a primary role for the HOD was that they ensured that teachers in technology departments understood what they should be doing. The other was that the HOD needed to encourage teachers to attend PD opportunities to support this. There is a close link between these two in that teachers see the importance of all technology teaching in the department as being both a continuum and progressive and that if not all teachers are 'up to speed,' this impacts on other teachers in the department. Teachers see an HOD role as supporting less experienced teachers with PD opportunities to overcome this.

Whilst some teachers considered that the HOD should run PD, others realised there was a range of constraints to this. Time was foremost; however, the skills of running a technology department were seen as different to the facilitation skills required for 
running effective PD programmes, and that often HOD knowledge needed to be updated just as teacher knowledge did.

Some teachers, however, preferred the 'one on one' environment for PD with their HOD and saw it as an advantage not needing to attend courses off site. Teachers working in small schools or departments tended to favour this approach.

\section{Teachers working together}

This category followed with 28 content units, $6.0 \%$ of the total. 'Teachers working together' was considered to be a separate category to 'Teachers sharing practice' within the data analysis although clearly they are closely linked. This difference was that teachers valued working with each other collaboratively during the PD learning process.

Within this category the highest number (8) of content units reported teachers valued talking to each other and working collaboratively on the development of their ideas and in particular unpacking what technological literacy and technology education looked like. Teachers felt that talking about and exchanging ideas and understandings was valuable, as there are a wide range of approaches appropriate to teaching technology and supporting students' technological learning.

Further to exchanging ideas, content units also showed that teachers valued working in groups and 'brainstorming', doing PD activities together, and participating in general discussion about the curriculum area and its recent developments.

Some teachers also felt that working together in groups during PD sessions supported their self-confidence, especially when the nature of this work was unpacking and discussing student outcomes which participants had supplied from their own classes.

\section{What works for me as a result of PD}

This category was fifth with 25 content units representing $5.3 \%$ of the total. This was the largest number of different content units within one category. The most common content unit was that PD in school helped some teachers. This is in line with other findings in the data where teachers report that follow-up to off-site PD by means of the facilitator/adviser visiting teachers in their schools was particularly effective in 
helping to individually contextualise the learning for teachers within their own school environment.

Within this category teachers reported that taking resources, worksheets, units and programme ideas, which they had developed at the PD session, back to school, along with modeling new practices, was beneficial to them. It helped them to structure courses supported by appropriate resources and teaching, which led to improved student achievement. This links with data in other categories such as 'Teachers working together' and 'Teachers sharing practice' where collaboration on critiquing existing resources and developing new ones for use in their classrooms was seen as highly effective.

Course participants communicating and working with each other in a variety of ways, including online, was also seen as supportive and enabled them to evaluate and 'process' their learning and implementation of new ideas. Teachers keeping in touch with each other electronically and looking collaboratively into aspects of teaching and student learning is in line with creating an online learning community as a supportive structure.

The main theme within this category was that as a result of attending PD, teachers' understandings were improved, enabling them to engage better with technology education and the pedagogy surrounding it when back in their schools. Examples of this were: structuring their courses to support students to be independent learners; developing school-wide systems to support technology education; getting new ideas and knowledge and implementing it; and learning about new teaching styles.

\section{Professional development types}

There are 23 content units in this category, ranking sixth overall and $57 \%$ of them refer to PD needing to be of a whole day structure, rather than a shorter timeframe, on a regular basis, and to be in depth. Teachers considered that a whole day set aside for PD was more effective than shorter courses. This indicates that teachers need time to engage with the PD in depth for it to be effective. There are links here to other data which showed teachers value in-depth and regular PD, and that short, 'one-off' sessions were less effective for their learning purposes. There is also a link 
to data concerning disadvantages of short sessions of PD delivered in school, during the school day, where some teachers felt that their heavy workloads prevented effective engagement in, and evaluation of, learning they experienced.

Within this category teachers also identified that the style of the PD had an influence on their engagement with it. A 'market place' or 'café' style PD supported by food was a preference for many. This involves varied groups of teachers working together on particular aspects of their learning. Similarly a 'what's on top, what's not' approach helped some teachers to identify and deal with particular aspects of knowledge they felt they lacked. Other teachers, who had experienced moderator training, where teachers trained to moderate internal assessment practice, felt that was their preference.

PD needing to be in a 'safe' environment where teachers were comfortable examining what they needed to learn and prepared to ask questions with confidence was a content unit in this category. The environment of where PD took place was of importance to some, with the majority of teachers preferring to work in a venue other than their own schools.

A key theme which runs through this category is that teachers value PD which is regular and continuing, in depth, and which is structured to support specific learning needs by working in groups.

\section{NZQA/NCEA PD}

There were 20 content units comprising $4.3 \%$ of the total concerned with this category. Half the content units (10) were concerned with national PD/training which took place in 2002 for NCEA Level 1; 2003 for Level 2; and 2004 for Level 3. Of this group (50\% of all content units for this category), half considered that the PD was inadequately facilitated and resourced whereas the other half stated that the training was valuable. The quality of the PD varied according to the skills of the facilitator and resources supplied by NZQA. Teachers' different perspectives on the effectiveness of this PD may be explained by this. Two content units within this group stated that national moderator training and adviser led PD was effective. 
The next highest number of content units within this category (20\%) was about NZQA requirements for senior assessment of technology constantly changing. Certainly there have been changes as assessment procedures of achievement standards have been developed and adapted; therefore this would support teachers' statements about the need for regular PD.

The remainder of the content units for this category was about resources to support teachers involved with assessing and moderating student work. Moderators' reports lacked real detail to support teacher understanding (2) and NZQA were slow to produce resources to support teaching and learning (1).

\section{Professional development facilitator practice}

This category was eighth in rank order and comprised 19 content units representing $4.1 \%$ of all categories. There was a spread of 15 different content units within this category and the highest number (3) stated that the Facilitator needs to visit teachers in their schools to support them in terms of their specific needs. Data in other categories indicate that some teachers value the facilitator visiting course participants as a follow-up to in-depth work in order to contextualise the learning for those teachers. Other data indicate that a small number of teachers prefer PD on an individual basis in their schools. However, more teachers value getting together and working collaboratively in order to engage with PD effectively.

Facilitator practice at PD short courses was less popular if it involved 'talking from the front' and reading through resources with teachers. Data showed that teachers recognised the need for directly transferring information, Information is most important (1), but that facilitator strategies to do this needed to be varied. Content units showed that value was placed on facilitator practice being flexible to accommodate individual and group needs, and on facilitators being open and approachable. Two content units referred to facilitators needing to contact teachers prior to the PD in order to identify learning required. Certainly gathering base-line data from participants prior to the event would ensure teachers' needs were being addressed.

Resources used to support the PD featured in four content units. Value was placed on these resources being in the form of exemplars and visual material rather than 
written documentation. One teacher stated 'I don't like the facilitator handing out paper and reading through it, I can do this by myself", and another preferred "concrete examples, not just talking”.

The use of ICT and visual presentations in multi-screen formats was mentioned in one content unit and making use of invited guest presenters was considered effective in another. The findings from the data indicate that facilitator practice is varied and that different approaches suit different teachers.

Several content units recognised that different facilitators had different styles but that good practice needed to be demonstrated by them (as the expert). Some teachers claimed to have worked with facilitators who "have not been respectful" and that they can have styles you either like, or you do not.

\section{Student work as exemplars}

This category consists of 18 content units (3.8\%). It ranks ninth and whilst it is a discrete category, the content units are linked to other categories within the data.

Teachers considered that the best support for them in terms of their understandings is to view successful student work in a PD environment, where they can question, critique and discuss it. All 18 content units support the view that working with examples of student work at PD sessions is effective for most teachers. However, value is still placed on using student work to support teacher and student understandings even if it is not used in a PD environment, for example DVD of student work is invaluable (1), and Keeping student work as exemplars (1).

The content units Teachers view successful work of students at professional development (5) and Best professional development shows student work and teacher practice (2) demonstrate the link between exemplary student work and teacher practice. Viewing student work alone is not enough; it is necessary to link it to teacher practice for participants of PD to gain a clear understanding. The teacher practice mentioned would include observing the context or brief on which the students' work is based and any assessment activities within the unit of work. 


\section{Synthesis of Categories}

In order to provide a further analysis of the data, categories were grouped based on degree of similarity or possible overlap in their content. Table 4.2 provides this information.

Table 4.2: Description and categories showing percentages and totals

\begin{tabular}{|c|c|c|c|}
\hline Description & Categories & Percentage & Total \% \\
\hline $\begin{array}{l}\text { Communities of } \\
\text { practice }\end{array}$ & $\begin{array}{l}\text { 1. Teachers sharing practice } \\
4 . \text { Teachers working together }\end{array}$ & $\begin{array}{l}9.6 \\
6.0\end{array}$ & 15.6 \\
\hline Content of PD & $\begin{array}{l}\text { 2. Content of professional development } \\
\text { 25. Curriculum (2007) support is needed } \\
\text { 33. PD opportunities in the past } \\
\text { 7. NZQA/NCEA professional development }\end{array}$ & $\begin{array}{l}8.7 \\
1.3 \\
1.1 \\
4.3\end{array}$ & 15.4 \\
\hline Types or form of PD & $\begin{array}{l}\text { 17. Follow-up PD is required } \\
\text { 19. School-wide PD } \\
\text { 6. PD Types } \\
\text { 23. Beacon Practice problems } \\
\text { 28. Beacon Practice successes } \\
\text { 29. Cluster meetings are important } \\
\text { 10. Delivery } \\
\text { 12. One on one with facilitator }\end{array}$ & $\begin{array}{l}2.1 \\
1.9 \\
4.9 \\
1.5 \\
1.1 \\
1.1 \\
2.8 \\
2.6\end{array}$ & 18 \\
\hline $\begin{array}{l}\text { Factors related to } \\
\text { what works/ inhibits } \\
\text { PD }\end{array}$ & $\begin{array}{l}\text { 5. What works for me as a result of professional } \\
\text { development } \\
\text { 13. Some professional development is ineffective } \\
\text { 15. Time is needed for professional development } \\
\text { 16. Problems with professional development } \\
\text { 24. Learning styles/types of learners } \\
\text { 27. Teacher attitudes } \\
\text { 30. Flexible } \\
\text { 32. Reading is important } \\
\text { 37. PD resources } \\
\text { 21. Visitors as a resource } \\
\text { 8. PD facilitator practice }\end{array}$ & $\begin{array}{l}5.3 \\
2.6 \\
2.3 \\
2.1 \\
1.5 \\
1.1 \\
1.1 \\
1.1 \\
0.9 \\
1.5 \\
4.1\end{array}$ & 23.6 \\
\hline Student focus & $\begin{array}{l}\text { 9. Student work as exemplars } \\
\text { 18. Improved student outcomes }\end{array}$ & $\begin{array}{l}3.8 \\
2.1\end{array}$ & 5.9 \\
\hline $\begin{array}{l}\text { School and teacher } \\
\text { change }\end{array}$ & $\begin{array}{l}\text { 11. Teacher change } \\
\text { 22. Changes in school and classroom } \\
\text { 36. Greater understanding of teaching practice in } \\
\text { technology }\end{array}$ & $\begin{array}{l}2.8 \\
1.5 \\
0.9\end{array}$ & 5.2 \\
\hline School support & $\begin{array}{l}\text { 34. School issues around professional development } \\
\text { 33. Limited professional development opportunities } \\
\text { 35. Funding needed }\end{array}$ & $\begin{array}{l}0.9 \\
1.1 \\
0.9\end{array}$ & 2.9 \\
\hline $\begin{array}{l}\text { Problems related to } \\
\text { 'new' technology }\end{array}$ & $\begin{array}{l}\text { 14. Technology is a difficult learning area for } \\
\text { teachers } \\
\text { 20. There are problems with some resources } \\
\text { 26. Technology teachers not trained in technology }\end{array}$ & $\begin{array}{l}2.3 \\
1.9 \\
1.1\end{array}$ & 5.3 \\
\hline Role of HOD & 3. Head of department role & 8.3 & 8.3 \\
\hline
\end{tabular}


This analysis has been done in order to examine the results of this thesis in relation to the earlier literature. This is discussed in the next chapter. The analysis of data did not attempt to support any particular model identified within the literature. The descriptions in Table 4.2, however, based on the similarities and possible overlap of categories, and their importance as can be seen by the total percentages, provides opportunity to consider links to the set of key considerations as shown in Table 2.3, developed by the researcher as a result of reviewing the literature.

\section{Summary}

Consideration of the categories, their rank order, and the content units within the most prominent ones shows that there are a number of common factors which emerge from the data. It seems clear that most teachers interviewed considered that having the opportunity to work together and share their practice at PD sessions in a collaborative manner, where they have the opportunity to examine, unpack and develop resources and build on their existing understandings and knowledge, is most beneficial to them. Further to this, the content of the PD being relevant to their specific needs is also vital for its effectiveness. The data indicate that these factors seem to be more important to the teachers interviewed, than any other aspects of PD and its facilitation. This and other findings are examined in Chapter Five. 


\section{Chapter Five: Discussion}

\section{Introduction}

Analysis of the data by means of content analysis (Berg, 2004) has allowed quantified categories to be created and ranked. Some categories are closely related but they have not been combined due to a different focus in the content units. This has provided richer data and analysis than would otherwise be the case. The categories have been identified in the 'Findings' section of this research. Consideration of the findings and a thorough review of literature have provided opportunity to answer the sub-questions within the main research question below. It should be noted that whilst there is a substantial body of literature and research on teacher PD, there is less information specific to technology teachers. However, consideration of the literature and the findings of this research indicate that there is much in common between effective PD of teachers from across curriculum areas, and technology teachers. This research also indicates that there is a wide range of characteristics of effective PD which support teacher learning (Hill et al., 2002; Mitchell \& Cubey, 2003; Timperley et al., 2007), and all of them apply just as much to technology teachers as they do to teachers of other curriculum areas. The difference for technology teachers, however, is that due to curriculum development requiring a broader technological capability across a range of technological areas, many teachers have had to learn new context specific knowledge and skills.

\section{Research Question}

From the perspective of technology heads of department and technology teachers, in what ways does teacher professional development support and improve technology teacher practice?

\section{Sub-Questions}

- How can technology teachers best be supported in their development and practice?

- What forms of professional development do technology teachers consider best supports and improves their practice? 
- In what ways do technology teachers view that effective professional development contributes to their practice?

- To what extent does teacher professional development facilitator (TPDF) practice influence the effectiveness of the professional development?

- What do heads of technology departments regard as most effective in supporting their technology teachers with changing their practice?

\section{How can technology teachers best be supported in their development and practice?}

There are two parts to consider with this sub-question. Firstly how technology teachers can best be supported in their development concerns technology teacher learning in terms of their subject and pedagogical knowledge.

The findings indicate that technology teachers benefit greatly from attending PD workshops which increase their level of understanding of this relatively new curriculum area. There are a number of reasons which emerge from the data as to why technology teachers need to develop their understandings but primarily it is the fact that the subject has been under constant change for the last fifteen years. It has grown from being a craft and skill-based technical education prior to 1975, through the stages of becoming workshop craft and for senior students, workshop technology, between the years 1975 and 1992. Technology education was established supported by Technology in the New Zealand Curriculum (Ministry of Education, 1995) which was gazetted in 1995. For the first time this identified the importance of developing technological literacy for students. Student learning was structured around three strands and eight achievement objectives across a range of technological areas. The introduction of the New Zealand Curriculum (Ministry of Education, 2007a) with its eight essential learning areas, one of which is technology, required further changes in terms of technology having three new strands and eight new achievement objectives. International and national research had identified a "new technological literacy" (Ministry of Education, 2007b, p. 14) which required the development of a broader and deeper technological literacy in students than had previously been the case.

Another major change affecting all secondary teachers has been the introduction of standards-based assessment in 2002. The change from the previous 'norm 
referenced' assessment system to assessment of student evidence against the relevant standards has been problematic for many teachers and still continues to be an issue for some. Teachers with continuing difficulties with this tended to experience less effective PD during the introductory years. The data in the category NZQA/NCEA professional development indicate an even split between teachers who were satisfied with this national PD and teachers who were not. PD therefore, has been key in developing teachers' understandings and confidence with this new system.

Further change is occurring presently in the form of a review and alignment of achievement standards with the new technology essential learning area and the New Zealand curriculum. The Institute of Professional Engineers, in association with the New Zealand Qualifications Authority, has been contracted by the Ministry of Education to do this, and they are developing a suite of new level 1 - 3 achievement standards at curriculum levels 6,7 and 8 which are aligned to the New Zealand Curriculum (Ministry of Education, 2007a). As teachers are responsible for assessing the internally assessed standards which are then moderated externally by sample, they need to have a clear understanding of the teaching and learning within programmes, as well as the assessment requirements of the standards in order for students to be successful. The data indicate that teachers feel a need for ongoing support with these issues and changes. The categories 'Professional development needed' and 'NZQA/NCEA Professional development' contain content units which indicate this. Clearly PD will be required if teachers are to make these transitions effectively.

Many teachers teaching technology education have not been trained in either content or pedagogy in a technology education context, to manage the changes occurring in the subject. The data indicate that teachers have a wide range of PD needs due to these changes which have occurred within the subject. Heads of technology are often in a similar situation, and as such, are often not in a position to provide effective PD for their department staff. Both heads of technology and technology teachers have relied on their own reading or PD opportunities provided by the network of School Support Services funded by the Ministry of Education under the School Support Services contract. In the above contexts then, heads of technology and technology teachers' development means their ability to upskill and embrace and implement the changes to the learning area which will support effective teaching and student learning. 
The second part to this sub-question concerns support for technology teacher practice, and how they can be supported in their ability to provide learning experiences for their students in line with curriculum requirements. Alton-Lee (2003) found that "Quality teaching is identified as a key influence on high quality outcomes for diverse students" (p. v). and further, "Teachers have knowledge of the nature of student learning processes in the curriculum area, can interpret student behaviour in the light of this knowledge and are responsive, creative and effective in facilitating learning processes" ( $p$ viii). Alton-Lee suggests that teachers' pedagogical knowledge, alongside curriculum knowledge, provides the best opportunity for student learning. Quality teaching in terms of teacher practice can be supported and student achievement can be improved therefore, where the teacher has access to PD and can benefit as a result of participation within it.

Analysis of the research data, particularly within the category What works for me as a result of professional development supports Alton-Lee's analysis and shows that teachers value and benefit from participation in PD. Teachers reported that using resources such as units of work, programmes and worksheets, along with ideas developed and explored during PD sessions, was 'beneficial' to them. The PD could have taken place in school or off site, and whilst there were different views as to which of these was most effective, they all agreed that participation in PD was most important, and that where it took place was a secondary issue. The data indicate that teacher understandings were improved, enabling them to engage better with the domain knowledge and pedagogical knowledge surrounding the subject. In particular, getting new ideas and knowledge, implementing it, and learning about new teaching styles were mentioned.

To summarise, the data indicate that technology teachers benefit from the opportunity to participate in PD which supports the development of their pedagogical content knowledge, and their ability to assess students' technological understandings. Timperley et al. (2007) also found the integration of content (p. 83) as a significant feature of many of the studies within the BES synthesis. This need for technology teachers has arisen as a result of the major changes which have occurred with the development of the subject over a number of years, and also includes the introduction of the New Zealand Curriculum (Ministry of Education, 2007a) and the 
technology essential learning area. Further to this, adoption of standards-based assessment in the senior years has placed another layer of change on planning and teaching in order for students to achieve. Support for technology teachers, therefore, requires effective, relevant and timely $\mathrm{PD}$, where resources and student work are examined and critiqued and teachers have the opportunity to consider student learning processes in the context of clear understandings of what technology education is.

\section{What forms of professional development do technology teachers consider best supports and improves their practice?}

Timperley et al. (2007), in their Best Evidence Synthesis Iteration, are given the remit: "If teachers, school leaders, and governments are going to expend energy and resources on professional learning, an understanding is needed about the kinds of learning that help teachers develop and grow in ways that will serve all their students well, even as expectations of students and schools are constantly changing” (p. x). Central to the Synthesis Iteration is that teacher PD is measured by the impact that it has on teacher practice and particularly on student achievement.

When we consider this sub-question, teachers' support and improvement in their practice is in the context of improved outcomes for diverse students, as a result of better teaching. It is through this lens that we need to view the data.

Analysis of all content units within the categories show that a number of factors emerge with respect to the forms of PD in which teachers engage. Whether this learning takes place in school or off site and whether it is of several hours, whole day or several days' duration is a factor for some. PD participants in large groups, smaller groups or one on one with the facilitator is a factor for others. The largest category within the data is 'Teachers sharing practice'. Many teachers agreed that 'sharing ideas with each other' was one of the most effective aspects of PD. Much of the literature identifies this as effective. Hill et al. (2002) identify collaboration between participants of PD, either during the actual workshops or subsequently, which supports a better understanding of a common goal of improving student outcomes. Timperley et al. (2009) discuss professional learning communities with a focus on a collaborative enquiry process. DuFour (2004) unpacks the advantages and 
issues around professional learning communities which also support improved student outcomes, particularly for those students at risk of underachieving. Garet et al. (2001) refer to collective participation of teachers, working together and being able to discuss pedagogical knowledge including issues and problems teachers face with this. Starkey et al. (2006) discuss issues around learning experiences for teachers and their ability to participate in a constructive peer feedback process.

Sharing resources, ideas, schemes of work, teaching strategies and experiences were all valued by teachers and particularly sharing and critiquing examples of student work.

The category Types of professional development is closely linked to this subquestion. Here teachers most often referred to wanting PD about domain knowledge (knowledge about the technology learning area) rather than pedagogical knowledge. This links back to the fact that technology has undergone such change that many teachers other than those more recently trained do not feel confident or competent in their knowledge of the subject and the pedagogy associated with effective delivery (Harwood \& Compton, 2007).

PD in the form of 'market place or cafe style' where teachers rotate in groups to different tables and explore particular themes, supported by food, was viewed as effective by many teachers. This indicates a less formal and more interactive approach suited some people well.

It should be noted, however, that collaboration does not necessarily work best for some teachers. Data from this research indicate that some teachers preferred a 'one on one' PD arrangement where there is a tight focus on individual requirements which may be specific to a particular teacher's teaching context. Teachers with this view, however, were very much in the minority.

In summary, the data strongly indicate that forms of PD which provide opportunity for teachers to work collaboratively and share ideas, resources and strategies for teaching technology, including 'unpacking' of student work, were effective for them. 
This aspect was more important for technology teachers than when, where, and for how long the PD took place.

\section{In what ways do technology teachers view that effective professional development contributes to their practice?}

All teachers interviewed considered that effective PD supported their learning and as a result they were able to use this new knowledge in their classrooms. The literature indicates that effective PD supports teacher learning which in turn leads to changed practice and improved student learning (Meiers \& Ingvarson, 2005; Timperley et al., 2007). A wide range of characteristics is identified in the literature which could support the notion of effectiveness; Mitchell and Cubey (2003) discuss building on participants' prior knowledge and skills which can lead to a development of theoretical and content knowledge by being critically effective of their own and others' practice. Timperley et al. (2007) considered effectiveness in terms of four 'overviews', namely context, content, learning activities, and learning processes. Effectiveness can also be viewed through a number of lenses, such as improved teacher knowledge - either content or pedagogy improved student outcomes, or more broadly such as encouraging teachers to work more collaboratively within or across schools and becoming more critically reflective of their own practice. All of these may be seen as aspects of effectiveness. Evaluation models which have been designed specifically for educational contexts such as Guskey's (2000) also unpack what effectiveness in PD means.

Analysis of the data for this research indicates that technology teachers view effective PD as contributing to their practice in many ways. Being in contact with other technology teachers, sharing practice and developing ideas and resources which they can take back to their schools and implement immediately was most common. Further to this examining and 'unpacking' aspects of student work which participants have brought with them is also a popular strategy which contributes to participants' practice. This may be because teachers see value in examining actual work students have done, and the ability to discuss it with the teacher who has implemented it.

There are a number of other categories within the data which refer to teachers' views of what contributes to their practice such as developing programmes and using them 
in classrooms; modelling that which has been discussed during PD and getting new ideas, understandings and clarifications in a range of areas such as assessment, research and pedagogical content knowledge. Consideration of the above may seem at first glance to be fundamental to what it is to be a technology teacher; however, teachers report a desire to up-skill in these areas which may be explained by a combination of factors. Namely the fundamental change and development of the subject, the fact that many technology teachers have not trained to teach the latest 'iteration' of the subject of technology, and the lack of relevant and up-to-date resources which have historically plagued the learning area.

To what extent does teacher professional development facilitator (TPDF) practice influence the effectiveness of the professional development?

Heads of department and teachers interviewed all agreed that the quality of facilitator practice had a major influence on its effectiveness. Ki te Aoturoa (Ministry of Education, 2008) makes explicit the links between facilitator practice, teacher learning and student outcomes (p. 14). Within one of the five principles this resource proposes is that facilitators need to be aware of teacher needs when running PD. The data from this research indicates teachers value the opportunity to have input into the PD focus and how facilitators work in a variety of ways.

Timperley et al. (2007) found that there is limited knowledge about the qualities of effective PD facilitators because of the lack of studies in this area, and although Ki te Aoturoa (Ministry of Education, 2008) progresses what is known, it is accepted within this resource that more research is required in this area.

The data from this research indicate that facilitator practice may be viewed in three ways: the practice of the facilitator prior to the PD; during the PD; the actions taken after the intervention.

Firstly, prior to the PD, some teachers considered there was value in being contacted by the facilitator to ascertain needs. This is further supported by content units from several categories which state the importance of the relevance of the programme. Literature also supports the view that effective, and therefore relevant PD content should build on, and challenge, participants' existing knowledge and beliefs 
(Mitchell \& Cubey, 2003; Starkey et al., 2006; Timperley et al., 2007). Not only should prior knowledge inform the content but the data indicate a need for flexibility on the part of the facilitator to adapt the programme according to specific needs of participants. Hill et al. (2002) cite Willis (2000) who discusses the importance of relevance of content relating to participants' particular teaching contexts. Gathering baseline data about participants' knowledge, skills and expectations of the professional learning experience can and should inform the content of the learning programme if it is to meet the varied needs of participating teachers. We might conclude then that facilitators need to be proactive in finding out and being aware of participants' knowledge and skills when planning PD.

Secondly, there were a number of content units which focused on facilitator practice during the intervention. The data highlighted views of a number of teachers who preferred to be in a learning environment which was teacher centred rather than led from the front by the facilitator. Timperley et al. (2007) identified an important aspect of effective PD was 'activities' where teachers engaged in a range of practical activities, linked to content, which allowed time for teachers to discuss and share understandings. Similarly these data showed a teacher preference for this pro-active learning style rather than teachers being issued with documentation which was examined by the facilitator up front. A preference also emerged that teachers needed to work with exemplars and visual evidence, rather than theory-based documentation.

Thirdly, the research data supported the view that teachers valued facilitator support after the PD intervention. Regular, in-depth and on-going PD was considered by many teachers as effective leading to teacher change in practice. Follow-up by the facilitator, either personally or online, was considered to add value to what has been learned in a number of ways including seeing teacher shifts in practice, allowing time for new learning to be implemented in terms of teacher practice, and being able to evaluate aspects of implementation. This is supported by a range of literature including Garet et al. (2001), Hill et al. (2002), and Meiers and Ingvarson (2005), who all discuss the advantages of longer in-depth PD rather than just attending short courses. 
The data indicate that some teachers have worked with facilitators who have not seemed respectful. Teachers have therefore not felt they were in a 'safe' environment in which to de-privatise their practice in order to examine how it might be improved. Rudman (1999) discusses the lack of teacher engagement in PD if teachers detect a lack of respect on the part of facilitators to participants. Hill et al. (2002) identify a characteristic of effective PD being that teachers need to feel they own the process and feel part of it rather than it being imposed on them. PD for technology teachers, therefore, needs to start with the facilitator being aware of the needs of the participants, and moving them on to the next steps in their learning. The ability to achieve this is dependent on facilitators having good, effective relationships with them and being flexible enough to be able to adapt to particular needs of participants. Both the data and literature indicate that facilitator practice has significant influence on the effectiveness of the PD for technology teachers.

\section{What do heads of technology departments regard as most effective in supporting their technology teachers with changing their practice?}

Analysis of the data gathered as a result of interviewing technology teachers, and examination of literature about effective PD for teachers generally indicates that there is much commonality between what is effective for both types of teachers. Further to this there was no discernable difference between what technology teachers with 0-5 years, 6-10 years, 11+ years' experience, and heads of department considered improved and supported their practice. No literature examined referred to different needs of technology teachers in terms of the length of time they had practised.

However, there were sufficient data concerning the role of the HOD for it to be the third largest category within the frequency table. The two highest content units with a frequency of 20 between them were that a key role of the HOD was to ensure teachers understand what they should be doing, and can encourage them to participate in PD opportunities. These may be facilitated by the HOD themselves, or by external facilitators. All HODs placed value on PD in terms of supporting their teachers with developing or changing practice, but two who worked in large schools were challenged in terms of time to facilitate effective PD. They did not feel there was enough time available to plan, prepare, deliver and evaluate PD effectively, or 
that teachers had enough time to participate given their other school responsibilities including their teaching. Two other HODs stated that they offered PD to individual teachers as the need became apparent. In both cases this was because the teachers concerned were not technology teachers, but were filling the role due to staff shortages and timetable requirements.

Issues with this which are problematic are that most HODs recognised that they needed to update their knowledge as much as their teachers and that facilitator skills were different to middle management skills such that some did not feel confident to plan, run and evaluate effective PD programmes. This is supported by data from this research which finds some teachers were aware of the limitations of some HODs in terms of time, recent or new knowledge and facilitation expertise. They considered the role of the adviser was to do just that. This could result in a lack of middle management leadership in some schools in terms of the HOD not being able to support their teachers. It is interesting to note that the Ministry of Education has placed emphasis on training and supporting middle management as a key output within school support service contracts for technology education for 2010, firmly indicating this area as a priority.

In summary the data firmly indicate that HODs of technology as well as technology teachers saw effective PD as supporting technology teachers in their practice.

\section{Conclusion}

This research has investigated how PD for technology teachers can support and improve technology teacher practice by examining the research question below:

From the perspective of technology heads of department and technology teachers, in what ways does teacher professional development support and improve technology teacher practice?

It has done this by gathering specific data from technology teachers and heads of technology in the form of teacher voice. A constructivist paradigm, an epistemology which argues that people create knowledge and meaning by reflecting on their past 
experiences and prior knowledge, has allowed the researcher to examine teachers' previous PD experiences, and content analysis has enabled the qualitative data of teacher voice to be coded, quantified and analysed. This has been informed by a wide range of national and international literature. It finds that technology teachers are no different to teachers from other curriculum areas in their needs for PD. However, changes in the curriculum for technology teachers over the past 15 years has been greater than in any other curriculum area. The data indicate that teachers, including heads of technology, require PD as a result of this, and the broad range of factors which define effective $\mathrm{PD}$, as identified in the literature, seems to be common to technology teachers.

This research finds that technology teachers' practice is supported through the opportunity to participate in PD which is effective, relevant and timely and where resources, teaching strategies and student work are examined and critiqued. Teachers then have the opportunity to consider student learning processes collaboratively. This can lead to the development of new ideas and understandings and the implementation of revised teaching programmes and practice. Teachers consider this to be most valuable. The ability to participate in this way was seen as more important than other factors such as where, when, and for how long the PD took place.

What seems to be critical in improving technology teacher practice is the development of pedagogical content knowledge, and ability to assess students' technological understandings, within high quality PD, building on teachers' existing knowledge and experiences within a constructivist theoretical framework. Facilitators need to identify teachers' learning needs so that PD content will move them forward. This places emphasis on the relationships facilitators develop with the technology teacher community. There are numerous content units within the data which indicate the importance of how the facilitator interacts and works with participants, including identifying learning needs for teachers. The data and literature indicate a considerable number of factors underlying effective PD. Effective relationships and the ability to be flexible and responsive to teachers' learning needs may be one of the most important. 
The data indicate that heads of department viewed PD in the same way as technology teachers, in that those interviewed placed value on PD supporting their practice. Teachers had expectations of their heads of department in providing opportunity for learning, whether it was facilitated by the HOD or an outside provider. What is important though is that professional learning should continue after the PD in a selfsustaining and collaborative learning environment where improved student achievement is the goal.

The review of literature has enabled the researcher to develop a set of nine key considerations, shown in Table 2.3, with respect to describing effective PD. They are as follows:

- Content of professional learning needs to consider learning theory, subject content knowledge, pedagogical content knowledge, and be linked to teachers' own classroom practice.

- Participants of professional learning should be able to 'own' the process by identifying their learning needs based on their students' learning needs and on critical self-reflection.

- New learning makes use of, challenges, and builds upon teachers' existing knowledge and conceptual understandings, and embraces their aspirations.

- PD helps teachers to change their practice, beliefs and understandings.

- Facilitators need to identify participants' prior knowledge, experience and learning needs, and plan content and activities accordingly.

- PD design should allow for participants to work collaboratively, sharing learning experiences and participating in constructive peer feedback. It should also provide opportunity for sharing experiences from within their own practice.

- PD should be hands-on and active, rather than passive learning.

- Participants should have the opportunity to evaluate the PD.

- The PD is more likely to impact positively on teacher learning and lead to a change in practice if it is sustained and intensive rather than of shorter duration. 
The synthesis of categories shown in Table 4.2 shows ten descriptions identified by merging overlapping categories. This indicates that teachers have significant experience based views and opinions on what works or inhibits effective PD for them. Most important is the type of PD which occurs as well as the content being appropriate for their learning needs and that they have the opportunity to engage with it in a collaborative manner. Teachers also considered that the HOD had a significant role in providing support for the PD process.

This thesis argues that technology teachers consider that they can be supported and their teaching practice improved if they engage in effective PD. The key considerations based on the literature may provide guidance for PD which may be considered effective. The categories may inform the content and type of PD taking place.

\section{Implications for my practice and that of others}

The findings from this research have had an impact on my own practice as a PD facilitator. Many of the key considerations have become part of my planning process and the prioritised categories have enabled me to further consider and adapt the content and method of delivery. This research may also be of value to others within the field of technology education PD by allowing them to link the key considerations of effective PD to the content and facilitation as identified within the categories and their descriptions.

\section{Further research opportunities}

As mentioned already, it is beyond the scope of this master's thesis to consider or measure improved student learning as a result of effective PD. It has been acknowledged that this is a limitation to this research. It may be necessary to develop a longitudinal study over several years in order to gather reliable data to unpack these links. Models such as those developed by Guskey and Sparks or Timperley may be of value in structuring and developing such work. This could provide opportunity for future $\mathrm{PhD}$ study. 


\section{References}

Alliger, G. M., \& Janak, E.A. (1989). Kirkpatrick's levels of training criteria: Thirty years later. Personal Psychology, 42(2), 331-342.

Alton-Lee, A. (2003). Quality teaching for diverse students in schooling: Best Evidence Synthesis. Wellington: Ministry of Education.

Annan, B., Kuin Lai, M., Robinson, V. (2003). Teacher talk to improve teacher practices. SET 1: Research, Practice and School Improvement, 31-37.

Atkin, J. (1996). From values and beliefs about learning to principles and practice. Seminar Series No.54. Melbourne: Incorporated Association of Registered Teachers of Victoria. Available at www.learningtolearn.sa.edu/Colleagues/ files/links/Values Beliefs.pdf

Bath, R. (2001). Learning by heart. Jossey Bass, SF: USA.

Berelson, B. (1952). Content analysis in communications research. Glencoe, IL: Free Press.

Berg, B. (2004). Qualitative research methods for the social sciences ( ${ }^{\text {th }}$ ed.). Boston: Pearson.

Bolam, R., McMahon, A., Stoll, L., Thomas, S., Wallace, M., with Greenwood, A., Hawkey, K., Ingram, M., Atkinson, A., Smith, M., (2005). Creating and sustaining effective professional learning communities (Research Report No. 637). University of Bristol Available online at www.dfes.gov.uk/research/data/ upload files/RR637.pdf

Cheetham, G., \& Chivers, G. (2000). A new look at competent professional practice. Journal of European Industrial Training, 24(7), 374-383.

Compton V. J. (2007). A new technological literacy. Paper provided as part of the Ministry of Education Curriculum Support Package published on Techlink at http://www.techlink.org.nz/curriculum-support/literacy/index.htm

Compton, A., \& Compton, V. J. (2010). Technological knowledge and nature of technology: Implications for teaching and learning. Research in progress.

Compton, V. J., \& France, B. (2006). Discussion document: Background information on the new strands. Faculty of Education. University of Auckland. Available from: http://nzcurriculum.tki.org.nz/Archives/Curriculum-project-archives/References

Compton, V., \& Jones, A. (1998). Reflecting on teacher development in technology education: Implications for future programmes. International Journal of Technology and Design Education, 8, 151-166.

Compton, V., Harwood, C. (2006). Discussion document: Design ideas for future technology programmes. Available at http://nzcurriculum.tki.org.nz/Archives/ Curriculum-project-archives/References

Denzin, N. K. (1978). The research act: a theoretical introduction to sociological methods. New York: McGraw-Hill. 
Denzin, N. L., \& Lincoln, Y. S. (2005). Introduction: The discipline and practice of qualitative research. In N. K. Denzin \& Y. S. Lincoln (Eds.), The handbook of qualitative research ( $3^{\text {rd }}$ ed.). Thousand Oaks, CA: Sage.

DuFour, R. (2004). What is a professional learning community? Journal of Educational Leadership, May, 6-11.

Education Review Office. (2009). Managing professional learning and development in secondary schools (May 2009). Retrieved from http://www.ero.govt.nz/ National-Reports/Managing-Professional_Learning-and-Development-inSecondary-Schools-May-2009

Ferguson, D. (2008). Development of technology education in New Zealand schools 1985 - 2008. Wellington: Ministry of Education.

Garet, M. S., Porter, A. C., Desimone, L., Birman, B. F. \& Yoon, K. S. (2001). What makes professional development effective? Results from a national sample of teachers. American Research Journal, 38(4), 915-940.

Glaser, B. G., \& Strauss, A. L. (1967). The discovery of grounded theory. Chicago: Aldine.

Grossman, P. (1990). The making of a teacher: Teacher knowledge and teacher education. New York: Teachers College Press, Columbia University.

Guskey, T. (2000). Evaluating professional development. Thousand Oaks, CA: Corwin.

Hall, C. (2007). Normative and interpretive research paradigms. Unpublished class handout, Victoria University of Wellington, School of Educational Studies.

Harwood, C. D., \& Compton, V. J. (2007). Moving from technical to technology education: Why it's so hard!! Paper presented at TENZ 2007 Conference.

Hill, J., Hawk, K., \& Taylor, K. (2002). Professional development: What makes it work? Set2, 3-5.

Holton, E. F. (1996). The flawed four-level evaluation model. Human Resource Development Quarterly, 7, 5-21.

Ingvarson, L. (2002). Building a learning profession. Australian College of Educators. Retrieved September 24, 2009, from www.acer.edu.au

Ingvarson, L., Meiers, M., \& Beavis, A. (2005). Factors affecting the impact of professional development programmes on teachers' knowledge, practice, student outcomes \& efficacy. Education Policy Analysis Archives, 13(10). Retrieved August 25, 2010, from http://epaa.asu.edu/epaa/v13n10/.

Jones, A. (2003). The development of a national curriculum in technology for New Zealand. International Journal of Technology and Design Education 13, 83-99.

Jones, A., \& Moreland, J. (2004). Enhancing practical primary school teachers' pedagogical content knowledge in technology. International Journal of Technology and Design Education, 14(2), 121-140. 
Jones, A., Harlow, A., \& Cowie, B. (2004). New Zealand teachers' experiences in implementing the technology curriculum. International Journal of Technology and Design Education 14, 101-119.

Kirkpatrick, D. L. (1976). Evaluation of training. In R. L. Craig (Ed.), Training and development handbook: A guide to human resource development $\left(2^{\text {nd }} \mathrm{ed}\right.$., $\mathrm{pp}$. 18.1-18.27). New York: McGraw-Hill.

Kirkpatrick, D. L. (1994). Evaluating training programs: The four levels. San Francisco: Berrett-Koehler.

Kraiger, K. (Ed.). (2002). Creating, implementing, and managing effective training and development. San Francisco: Jossey-Bass.

Loucks-Horsley, S., Hewson, P. W., Love, N., \& Stiles, K. F. (1998). Designing professional development for teachers of science and mathematics. Thousand Oaks, CA: Corwin Press.

Meiers, M., \& Ingvarson, L. (2005). Investigating the links between teacher professional development and student learning outcomes. Australian Council for Educational Research. Australia. Retrieved June 23, 2010, from http://www.dest.gov.au/NR/rdonlyres/993A693A-3604-400F-AB8157F70A8A83A6/8039/Vol1Rev_Final_26Sept05.pdf

Ministry of Education. (1995). Technology in the New Zealand curriculum. Wellington: Learning Media.

Ministry of Education. (2002). Curriculum stocktake report to Minister of Education, September 2002. Retrieved August 15, 2010, from http://www.educationcounts. govt.nz/publications/curriculum/5815

Ministry of Education. (2005). Schooling strategy 2005-2010. Wellington: Ministry of Education.

Ministry of Education. (2007a). The New Zealand curriculum. Wellington: Learning Media.

Ministry of Education. (2007b). Technology curriculum support. Available from: http://www.techlink.org.nz/curriculum-support/pdfs/technology-curriculumsupport-2010.pdf

Ministry of Education. (2008). Ki te Aoturoa: Improving inservice teacher learning and practice. Wellington: Learning Media.

Mitchell, L., \& Cubey, P. (2003). Characteristics of effective professional development linked to enhanced pedagogy and children's learning in early childhood settings: Best evidence synthesis. Wellington: Ministry of Education.

Mutch, C. (2005). Doing educational research: A practitioner's guide to getting started. Wellington: NZCER Press.

National Staff Development Council. (2001). National Staff Development Council's standards for staff development (Rev. ed.). Oxford: Author. Available at http://www.nsdc.org/library/standards2001.html 
Neuman, W. L. (1994). Social research methods: Qualitative and quantitative approaches. Boston: Allyn \& Bacon.

Nixon, M. (2004). Getting under the skin of NCEA. New Zealand Education Review, 9(30), 7-8.

Poskitt, J. (2005). Towards a model of New Zealand school-based teacher professional development. New Zealand Journal of Teachers' Work, 2(2), 136151.

Praslova, L. (2009). Adaptation of Kirkpatrick's four level model of training criteria to assessment of learning outcomes and program evaluation in higher education. Educational Assessment, Evaluation and Accountability. Retrieved May 25, 2010, from http://www.springerlink.com.helicon.vuw.ac.nz/content/ b150h14718512713/fulltext.html

Rohaan, E.J. (2009). Testing teacher knowledge for technology teaching in primary schools. Eindhoven: Printservice TU/e.

Rudman, R. S. (1999) Human resources management in New Zealand. Auckland: Addison Wesley.

Salas, E., \& Cannon-Bowers, J. A. (2001). The science of training: a decade of progress. Annual Review of Psychology, 52, 472-499.

Showers, J., \& Joyce, B. (1996). The evolution of peer coaching. Educational Leadership, March, 12-16.

Shulman, L. (1987). Knowledge and teaching: Foundations of the new reform. Harvard Educational Review, 57(1), 1-22.

Starkey, L., Stevens, S., Taylor, M., Toia, R., Yates, A., Hall, C. et al. (2006). School/cluster based secondary qualifications professional development: Review of secondary schools' use of NCEA professional development resources, 2005-2006. Wellington: Ministry of Education Research Division.

Stoll, L., \& Fink, D. (1996) Changing our schools. Buckingham, Philadelphia. USA.

Strauss, A. L. (1987). Qualitative analysis for social scientists. New York: Cambridge University Press.

Timperley, H., \& Parr, J. (2004). Using evidence in teaching practice: Implications for professional learning. Auckland: Hodder Moa Beckett.

Timperley, H., \& Robinson, M. J. (2001). Achieving school improvement through challenging and changing teachers' schema. Journal of Educational Change, 2, 281-300.

Timperley, H., Parr, J., \& Bertanees, C. (2009). Promoting professional inquiry for improved outcomes for students in New Zealand. Professional Development in Education, 35(2), 227-245.

Timperley, H., Wilson, A., Barrar, H., \& Fung, I., (2007). Teacher professional learning and development: Best evidence synthesis iteration. Wellington: Ministry of Education. 
Van Driel, J., Verloop, N., \& De Vos, W. (1998). Developing science teachers' pedagogical content knowledge. Journal of Research in Science Teaching, 35 (6), 673-695.

Willis, D. (2000) Adult learning and the professional development of teachers. Wellington: An unpublished paper prepared for the Education Review Office by Victoria University.

Yin, R. K. (2003). Case study research design methods ( $3^{\text {rd }}$ ed.). Thousand Oaks, CA: Sage. 


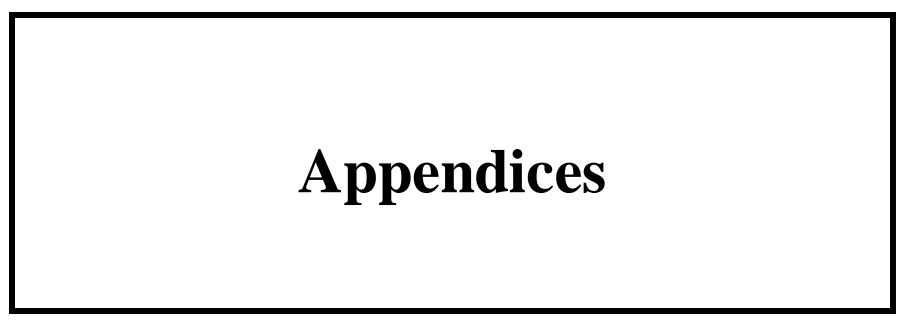




\section{Appendix 1: Data Frequency Table}

\begin{tabular}{|c|c|c|c|c|}
\hline Rank & Categories with content units & Frequency & $\%$ & $\begin{array}{c}\text { Cumulative } \\
\%\end{array}$ \\
\hline \multirow[t]{18}{*}{1} & Teachers sharing practice & 45 & 9.6 & 9.6 \\
\hline & Sharing ideas with other teachers works well & 18 & & \\
\hline & $\begin{array}{l}\text { Teachers attend PD and bring back information to share } \\
\text { with the department. }\end{array}$ & 5 & & \\
\hline & $\begin{array}{l}\text { Teachers share resources and improve on them through } \\
\text { the PD }\end{array}$ & 2 & & \\
\hline & Contact with other teachers and sharing ideas & 2 & & \\
\hline & Sharing examples of student work & 3 & & \\
\hline & Sharing resources works well & 2 & & \\
\hline & Working on schemes together & 2 & & \\
\hline & All participants need to bring work to share & 2 & & \\
\hline & Sharing practice and getting suggestions from others & 1 & & \\
\hline & Cooperative learning and sharing & 1 & & \\
\hline & Teachers share PD opportunities according to need & 1 & & \\
\hline & Only a small group of people share and attend & 1 & & \\
\hline & Interactive PD is best where we share ideas & 1 & & \\
\hline & Sharing strategies with other HODs & 1 & & \\
\hline & Sharing practice in school & 1 & & \\
\hline & Teachers sharing experiences & 1 & & \\
\hline & Sharing practice helps create a community & 1 & & \\
\hline \multirow[t]{24}{*}{2} & Content of professional development & 41 & 8.7 & 18.3 \\
\hline & Domain knowledge rather than pedagogy & 6 & & \\
\hline & Need subject specific PD & 5 & & \\
\hline & PD on language writing & 4 & & \\
\hline & Moderator training great PD & 3 & & \\
\hline & Subject association & 3 & & \\
\hline & PD needs to be relevant and open to understanding & 2 & & \\
\hline & Practical ICT PD needed ... kskills based. & 2 & & \\
\hline & Relevant up to date information at PD is important & 1 & & \\
\hline & $\begin{array}{l}\text { Combination of PD needed, senior assessment and skills } \\
\text { development }\end{array}$ & 1 & & \\
\hline & $\begin{array}{l}\text { PD style 'what's on top, what's not' often solves } \\
\text { problems }\end{array}$ & 1 & & \\
\hline & Cross Curricular approach to PD & 1 & & \\
\hline & PD supported programme planning & 1 & & \\
\hline & $\begin{array}{l}\text { Teacher practice is supported by PD at College or } \\
\text { University }\end{array}$ & 1 & & \\
\hline & $\begin{array}{l}\text { PD needs to differ according to how long you have been } \\
\text { teaching }\end{array}$ & 1 & & \\
\hline & $\begin{array}{l}\text { PD experiences other than subject specific technology is } \\
\text { also important }\end{array}$ & 1 & & \\
\hline & PD on NZC 2007 needed & 1 & & \\
\hline & $\begin{array}{l}\text { Need more PD on NCEA assessment practice and senior } \\
\text { assessment generally }\end{array}$ & 1 & & \\
\hline & PD on classroom management skills needed & 1 & & \\
\hline & Need support to re write some programmes & 1 & & \\
\hline & HODs need PD to support their teachers & 1 & & \\
\hline & $\begin{array}{l}\text { I never had PD in technology before the recent in depth } \\
\text { work }\end{array}$ & 1 & & \\
\hline & Deadlines for ERO & 1 & & \\
\hline & $\begin{array}{l}\text { PD where teachers go away with information to make life } \\
\text { easier }\end{array}$ & 1 & & \\
\hline
\end{tabular}




\begin{tabular}{|c|c|c|c|c|}
\hline Rank & Categories with content units & Frequency & $\%$ & $\begin{array}{c}\text { Cumulative } \\
\%\end{array}$ \\
\hline \multirow[t]{15}{*}{3} & HOD Role & 39 & 8.3 & 26.6 \\
\hline & $\begin{array}{l}\text { HOD role is to ensure teachers understand what they } \\
\text { should be doing }\end{array}$ & 10 & & \\
\hline & Can encourage teachers to attend PD & 10 & & \\
\hline & Offers PD as required on a needs basis & 4 & & \\
\hline & Sets an example for the rest of the department & 3 & & \\
\hline & HOD provides good PD & 2 & & \\
\hline & HOD is good at informing staff of PD opportunities & 2 & & \\
\hline & Needs to be supported in implementing new ideas & 1 & & \\
\hline & HOD can use PD to drive change & 1 & & \\
\hline & HOD does 1 on 1 PD with teachers when necessary & 1 & & \\
\hline & $\begin{array}{l}\text { An HOD of a large school is challenged to provide } \\
\text { effective PD }\end{array}$ & 1 & & \\
\hline & Lack of time for HODs to be effective PD facilitators & 1 & & \\
\hline & HODs should enforce PD on reluctant teachers & 1 & & \\
\hline & I don't work closely with other teachers except my HOD & 1 & & \\
\hline & HODs need to be aware of their teachers needs & 1 & & \\
\hline \multirow[t]{15}{*}{4} & Teachers working together & 28 & 6.0 & 32.6 \\
\hline & Good to talk to other tech teachers about ideas & 8 & & \\
\hline & Seeing other teachers work and ideas is powerful & 4 & & \\
\hline & Talking and swapping notes is useful & 3 & & \\
\hline & Unpacking technological practice with other teachers & 2 & & \\
\hline & Good to talk to HODs from other schools & 2 & & \\
\hline & Teachers working in groups to brainstorm & 1 & & \\
\hline & Technology teachers need to work together & 1 & & \\
\hline & $\begin{array}{l}\text { Facilitators and others help new teachers by sharing their } \\
\text { time }\end{array}$ & 1 & & \\
\hline & Working in groups supports self confidence & 1 & & \\
\hline & General discussion at PD sessions helpful & 1 & & \\
\hline & $\begin{array}{l}\text { Good to work with other teachers and doing activities } \\
\text { with them }\end{array}$ & 1 & & \\
\hline & General discussion at PD sessions helpful & 1 & & \\
\hline & $\begin{array}{l}\text { PD where teachers bring student work to discuss is really } \\
\text { effective. }\end{array}$ & 1 & & \\
\hline & Getting resources from other participants & 1 & & \\
\hline \multirow[t]{13}{*}{5} & $\begin{array}{l}\text { What works for me as a result of professional } \\
\text { development }\end{array}$ & 25 & 5.3 & 37.9 \\
\hline & PD support in school has helped me & 4 & & \\
\hline & $\begin{array}{l}\text { Need time to reflect on successes and failures at the time, } \\
\text { i.e. ongoing evaluation. }\end{array}$ & 2 & & \\
\hline & $\begin{array}{l}\text { Develop programmes and bring the information back to } \\
\text { school }\end{array}$ & 1 & & \\
\hline & I share PD resources I get with students & 1 & & \\
\hline & Modelling what I have seen is most effective & 1 & & \\
\hline & Developed worksheets & 1 & & \\
\hline & Moderator feedback embedded in PD & 1 & & \\
\hline & $\begin{array}{l}\text { Structuring my courses to support students to be } \\
\text { independent learners }\end{array}$ & 1 & & \\
\hline & PD can generate a system that works & 1 & & \\
\hline & $\begin{array}{l}\text { PD has helped the HOD get consistency across the } \\
\text { department }\end{array}$ & 1 & & \\
\hline & Developing school wide strategies & 1 & & \\
\hline & Lunchtime chats (teacher talk) e.g. Annan & 1 & & \\
\hline
\end{tabular}




\begin{tabular}{|c|c|c|c|c|}
\hline Rank & Categories with content units & Frequency & $\%$ & $\underset{\%}{\text { Cumulative }}$ \\
\hline & Analysis of ideas & 1 & & \\
\hline & I always get new ideas and knowledge from PD & 1 & & \\
\hline & $\begin{array}{l}\text { Going through technological practice and talking to a } \\
\text { professional technologist }\end{array}$ & 1 & & \\
\hline & Facilitators answer questions and share time. & 1 & & \\
\hline & PD clarifies senior assessment requirements & 1 & & \\
\hline & $\begin{array}{l}\text { Working through a unit to see what you will teach the } \\
\text { students }\end{array}$ & 1 & & \\
\hline & Online exchanges after PD & 1 & & \\
\hline & Learning about new teaching styles is good & 1 & & \\
\hline & PD has established common assessment practice for me & 1 & & \\
\hline 6 & PD Types & 23 & 4.9 & 42.8 \\
\hline & Regular PD needed to keep 'up to speed' & 6 & & \\
\hline & Market place or Café style PD supported by food & 4 & & \\
\hline & VUW PD at university campus are good & 4 & & \\
\hline & Clear day makes PD more focused & 1 & & \\
\hline & 1 day short courses for information & 1 & & \\
\hline & Whole day PD good & 1 & & \\
\hline & $\begin{array}{l}\text { Continuing and regular PD helps focus teachers to } \\
\text { change }\end{array}$ & 1 & & \\
\hline & PD needs to be in a 'safe' environment for teachers & 1 & & \\
\hline & Need longer in depth PD rather than one of sessions & 1 & & \\
\hline & Whole day PD broken up into sessions & 1 & & \\
\hline & PD meetings at school & 1 & & \\
\hline & High tech ICT will aid PD in the future & 1 & & \\
\hline 7 & NZQA/NCEA Professional development & 20 & 4.3 & 47.1 \\
\hline & $\begin{array}{l}\text { National NCEA training inadequately resourced and } \\
\text { facilitated }\end{array}$ & 5 & & \\
\hline & National NCEA training was valuable & 5 & & \\
\hline & NZQA requirements for technology constantly change & 4 & & \\
\hline & NZQA are slow to produce resources & 2 & & \\
\hline & Moderators reports lack real detail & 1 & & \\
\hline & Moderator training was good PD & 1 & & \\
\hline & National PD handouts and exemplars are good. & 1 & & \\
\hline & Advisor led PD off campus good for NCEA & 1 & & \\
\hline 8 & Professional development facilitator practice & 19 & 4.1 & 51.2 \\
\hline & Facilitator needs to visit teachers to support them. & 3 & & \\
\hline & Facilitators could invite teachers they know need help & 2 & & \\
\hline & $\begin{array}{l}\text { Sessions run by several facilitators and teachers pick and } \\
\text { choose from what's on offer }\end{array}$ & 2 & & \\
\hline & $\begin{array}{l}\text { Building and maintaining a network is hard for } \\
\text { facilitators }\end{array}$ & 1 & & \\
\hline & $\begin{array}{l}\text { Facilitator planning multi screen presentations for } \\
\text { Graphics PD }\end{array}$ & 1 & & \\
\hline & $\begin{array}{l}\text { Facilitators need exemplars and visual evidence rather } \\
\text { than just theory }\end{array}$ & 1 & & \\
\hline & Facilitators can move on to what people need easily & 1 & & \\
\hline & Some facilitators have not been respectful & 1 & & \\
\hline & $\begin{array}{l}\text { Don't like facilitator handing out paper and reading } \\
\text { through it, I can do this by myself. }\end{array}$ & 1 & & \\
\hline & $\begin{array}{l}\text { Facilitators could contact teachers prior to PD to } \\
\text { ascertain learning needs }\end{array}$ & 1 & & \\
\hline & Facilitators need to be open and approachable & 1 & & \\
\hline
\end{tabular}




\begin{tabular}{|c|c|c|c|c|}
\hline Rank & Categories with content units & Frequency & $\%$ & $\begin{array}{c}\text { Cumulative } \\
\%\end{array}$ \\
\hline & $\begin{array}{l}\text { Good practice needs to be demonstrated by expert } \\
\text { (facilitator) }\end{array}$ & 1 & & \\
\hline & Facilitators have styles you like or don’t like. & 1 & & \\
\hline & Facilitator talking up front not so good. & 1 & & \\
\hline & Information is most important & 1 & & \\
\hline \multirow[t]{14}{*}{9} & Student work as exemplars & 18 & 3.8 & 55.0 \\
\hline & Teachers view successful work of students at PD & 5 & & \\
\hline & Best PD shows student work and teacher practice & 2 & & \\
\hline & Keeping student work as exemplars & 1 & & \\
\hline & $\begin{array}{l}\text { Show the theory on screen accompanied by student work } \\
\text { examples }\end{array}$ & 1 & & \\
\hline & DVD of student work invaluable & 1 & & \\
\hline & $\begin{array}{l}\text { Run PD in the classrooms with student exemplar work } \\
\text { available. }\end{array}$ & 1 & & \\
\hline & $\begin{array}{l}\text { PD needs quality student exemplar material and } \\
\text { assessment examples available }\end{array}$ & 1 & & \\
\hline & Informed facilitators with good exemplars available & 1 & & \\
\hline & $\begin{array}{l}\text { PD where teachers bring student work to discuss is really } \\
\text { effective. }\end{array}$ & 1 & & \\
\hline & Concrete examples, not just talking & 1 & & \\
\hline & Need a good environment with student work on the walls & 1 & & \\
\hline & PD in a practical environment with exemplars available & 1 & & \\
\hline & Examples of student work essential & 1 & & \\
\hline \multirow[t]{8}{*}{10} & Delivery & 13 & 2.8 & 55.8 \\
\hline & Smaller flexible groups is good & 5 & & \\
\hline & Short $2 \mathrm{hr}$ sessions & 2 & & \\
\hline & Using ICT as a presentation tool & 2 & & \\
\hline & Active PD rather than just listening & 1 & & \\
\hline & Team facilitation is good. & 1 & & \\
\hline & PD needs good content and delivery & 1 & & \\
\hline & $\begin{array}{l}\text { Use of ICT i.e. multi screen presentations of student } \\
\text { work }\end{array}$ & 1 & & \\
\hline \multirow[t]{13}{*}{11} & Teacher Change & 13 & 2.8 & 58.6 \\
\hline & I've changed my practice as a result of PD & 2 & & \\
\hline & $\begin{array}{l}\text { Student presentation of work is now my focus because it } \\
\text { was poor }\end{array}$ & 1 & & \\
\hline & My teaching has changed as a result & 1 & & \\
\hline & I'm now looking at kids analytical comments & 1 & & \\
\hline & PD has enabled me to reflect on other teachers practice & 1 & & \\
\hline & PD has impacted positively on my classroom practice. & 1 & & \\
\hline & $\begin{array}{l}\text { Teachers are often not prepared to change what they do } \\
\text { unless they see examples }\end{array}$ & 1 & & \\
\hline & $\begin{array}{l}\text { Continuing and regular PD helps focus teachers to } \\
\text { change }\end{array}$ & 1 & & \\
\hline & $\begin{array}{l}\text { Teachers have a better understanding since the } \\
\text { professional development. }\end{array}$ & 1 & & \\
\hline & Students evaluate my performance so I can improve it & 1 & & \\
\hline & I'm involved with research at school & 1 & & \\
\hline & School wide PD has supported my pedagogy & 1 & & \\
\hline \multirow[t]{3}{*}{12} & 1 on 1 PD with facilitator & 12 & 2.6 & 61.2 \\
\hline & One on one tutoring is great for me & 4 & & \\
\hline & 1 on 1 PD works well & 3 & & \\
\hline
\end{tabular}




\begin{tabular}{|c|c|c|c|c|}
\hline Rank & Categories with content units & Frequency & $\%$ & $\begin{array}{c}\text { Cumulative } \\
\%\end{array}$ \\
\hline & 1on 1 is tightly focused & 1 & & \\
\hline & Whole day 1 on 1 with Advisor & 1 & & \\
\hline & $\begin{array}{l}\text { Working with teachers } 1 \text { on } 1 \text { skills based PD if } \\
\text { necessary }\end{array}$ & 1 & & \\
\hline & 1 on 1 with the facilitator & 1 & & \\
\hline & One on one with Advisor or HOD is best for me & 1 & & \\
\hline \multirow[t]{7}{*}{13} & Some PD is ineffective & 12 & 2.6 & 63.8 \\
\hline & $\begin{array}{l}\text { Lots of PD content can be irrelevant and therefore boring } \\
\text { to participants }\end{array}$ & 4 & & \\
\hline & $\begin{array}{l}\text { Generic school based PD doesn't work well for } \\
\text { technology teachers }\end{array}$ & 3 & & \\
\hline & $\begin{array}{l}\text { In school short PD sessions are less effective because of } \\
\text { school teaching pressures }\end{array}$ & 2 & & \\
\hline & PD needs to have direction & 1 & & \\
\hline & PD not reflected in the classroom & 1 & & \\
\hline & $\begin{array}{l}\text { Subject PD facilitated by someone who had never taught } \\
\text { the subject }\end{array}$ & 1 & & \\
\hline \multirow[t]{8}{*}{14} & Technology is a difficult learning area for teachers & 12 & 2.6 & 66.4 \\
\hline & There are problems with the T in NZC (1995) & 3 & & \\
\hline & $\begin{array}{l}\text { Technology Education is not an easy area, teachers need } \\
\text { lots of PD }\end{array}$ & 3 & & \\
\hline & $\begin{array}{l}\text { Technology education has become so complex it is } \\
\text { difficult for teachers to understand it. }\end{array}$ & 2 & & \\
\hline & $\begin{array}{l}\text { You are always on the back foot with your understanding } \\
\text { of a changing curriculum. }\end{array}$ & 1 & & \\
\hline & $\begin{array}{l}\text { I frequently work with technology teachers who are } \\
\text { negative about it. }\end{array}$ & 1 & & \\
\hline & The language of the technology curriculum is a problem & 1 & & \\
\hline & We haven't been teaching to the curriculum & 1 & & \\
\hline \multirow[t]{7}{*}{15} & Time is needed for PD & 11 & 2.3 & 68.7 \\
\hline & Time for PD is an issue for me & 5 & & \\
\hline & Time allowance in my timetable needed for PD & 2 & & \\
\hline & Too busy to attend conferences & 1 & & \\
\hline & I can only attend PD in my own time & 1 & & \\
\hline & I don't have time to reflect on the PD I've done. & 1 & & \\
\hline & Too busy for much in school PD & 1 & & \\
\hline \multirow[t]{6}{*}{16} & Problems with PD & $\mathbf{1 0}$ & 2.1 & 70.8 \\
\hline & $\begin{array}{l}\text { Information is not always available and therefore doesn't } \\
\text { answer all the questions }\end{array}$ & 4 & & \\
\hline & Attendance is poor at cluster/PD sessions & 2 & & \\
\hline & $\begin{array}{l}\text { PD content needs to be specific to participants, i.e.,HODs } \\
\text { or PRTs }\end{array}$ & 2 & & \\
\hline & Technology PD needs to cover skills teaching & 1 & & \\
\hline & Application of theory is a problem & 1 & & \\
\hline \multirow[t]{6}{*}{17} & Follow up to PD is required & 10 & 2.1 & 72.9 \\
\hline & PD with follow up is effective & 3 & & \\
\hline & Follow up to PD sessions is needed to see teacher shifts & 2 & & \\
\hline & In depth PD needs follow up & 2 & & \\
\hline & $\begin{array}{l}\text { Follow up with time to allow for implementation of } \\
\text { changes }\end{array}$ & 2 & & \\
\hline & Follow up to PD allows for sharing experiences & 1 & & \\
\hline
\end{tabular}




\begin{tabular}{|c|c|c|c|c|}
\hline Rank & Categories with content units & Frequency & $\%$ & $\begin{array}{c}\text { Cumulative } \\
\%\end{array}$ \\
\hline \multirow[t]{11}{*}{18} & Improved Student Outcomes & 10 & 2.1 & 75.0 \\
\hline & Activities immediately got kids working & 1 & & \\
\hline & Students writing improved as a result of my PD & 1 & & \\
\hline & Applied Blooms Taxonomy to students writing. & 1 & & \\
\hline & One day PD has helped improve grades & 1 & & \\
\hline & Student results improved dramatically & 1 & & \\
\hline & Students respond well to BP exemplars & 1 & & \\
\hline & $\begin{array}{l}\text { All schools need to take responsibility to raise student } \\
\text { achievement }\end{array}$ & 1 & & \\
\hline & PD on 'flying in five' useful & 1 & & \\
\hline & $\begin{array}{l}\text { Students are failing due to lack of PD for some teachers } \\
\text { in schools }\end{array}$ & 1 & & \\
\hline & Image rich classroom is powerful & 1 & & \\
\hline \multirow[t]{5}{*}{19} & School wide PD & 9 & 1.9 & 76.9 \\
\hline & In house school wide PD & 6 & & \\
\hline & In school PD focused on professional practice & 1 & & \\
\hline & $\begin{array}{l}\text { Whole school PD was too generic, teachers already knew } \\
\text { a lot of it. }\end{array}$ & 1 & & \\
\hline & One on one PD works best for this school & 1 & & \\
\hline \multirow[t]{7}{*}{20} & There are problems with some resources & 9 & 1.9 & 78.8 \\
\hline & Navigation to web based resources is clumsy & 2 & & \\
\hline & $\begin{array}{l}\text { Existing web based technology is too slow to be really } \\
\text { effective }\end{array}$ & 2 & & \\
\hline & $\begin{array}{l}\text { There are problems with poor resources for the learning } \\
\text { area. }\end{array}$ & 2 & & \\
\hline & Not all teachers have access to laptops & 1 & & \\
\hline & $\begin{array}{l}\text { Teachers have to pay themselves when they access online } \\
\text { resources from home. }\end{array}$ & 1 & & \\
\hline & Need better electronic storage facilities for ICT & 1 & & \\
\hline \multirow[t]{4}{*}{21} & Visitors as a resource & 7 & 1.5 & 80.3 \\
\hline & Experts are needed to visit classrooms to support teachers & 5 & & \\
\hline & Teachers and schools want support on a regular basis & 1 & & \\
\hline & Outside speakers need to visit schools & 1 & & \\
\hline \multirow[t]{7}{*}{22} & Changes in school/classroom & 7 & 1.5 & 81.8 \\
\hline & $\begin{array}{l}\text { Teaching is more enjoyable with good professional } \\
\text { development. }\end{array}$ & 2 & & \\
\hline & $\begin{array}{l}\text { Department is more integrated since the professional } \\
\text { development. }\end{array}$ & 1 & & \\
\hline & $\begin{array}{l}\text { Learning community created in school as a result of } \\
\text { professional development. }\end{array}$ & 1 & & \\
\hline & Improved classroom management & 1 & & \\
\hline & $\begin{array}{l}\text { Department is more integrated since the professional } \\
\text { development. }\end{array}$ & 1 & & \\
\hline & $\begin{array}{l}\text { There is a more consistent approach since the } \\
\text { professional development. }\end{array}$ & 1 & & \\
\hline \multirow{3}{*}{23} & Beacon Practice problems & 7 & 1.5 & 83.3 \\
\hline & $\begin{array}{l}\text { Beacon Practice exemplar images are too small and have } \\
\text { too many words to explain them }\end{array}$ & 2 & & \\
\hline & $\begin{array}{l}\text { Assumption that teachers were at a certain level with } \\
\text { technological practice. }\end{array}$ & 1 & & \\
\hline
\end{tabular}




\begin{tabular}{|c|c|c|c|c|}
\hline \multirow[t]{5}{*}{ Rank } & Categories with content units & Frequency & $\%$ & Cumulative \\
\hline & $\begin{array}{l}\text { Access to Beacon Practice teachers is difficult and } \\
\text { clumsy }\end{array}$ & 1 & & \\
\hline & $\begin{array}{l}\text { Teachers need to visit the Beacon Practice teachers to } \\
\text { contextualize the exemplars }\end{array}$ & 1 & & \\
\hline & $\begin{array}{l}\text { Had difficulty with interacting with Beacon Practice } \\
\text { teachers, took too long }\end{array}$ & 1 & & \\
\hline & $\begin{array}{l}\text { Lack of clarity of practice, exemplars need better } \\
\text { annotation }\end{array}$ & 1 & & \\
\hline \multirow[t]{8}{*}{24} & Learning styles/ types of learners & 7 & 1.5 & 84.8 \\
\hline & Visual learners need notes given out. & 1 & & \\
\hline & Some teachers don't learn well by just listening. & 1 & & \\
\hline & I need to see examples, do it, hear it, try it out. & 1 & & \\
\hline & I'm poor at understanding pedagogy. & 1 & & \\
\hline & I learn best by seeing and doing & 1 & & \\
\hline & Ideas posted on wall at the end & 1 & & \\
\hline & PD is essential for enthusiastic teachers & 1 & & \\
\hline \multirow[t]{4}{*}{25} & Curriculum 2007 support is needed & 6 & 1.3 & 86.1 \\
\hline & $\begin{array}{l}\text { PD on developing information to support the new } \\
\text { curriculum needed }\end{array}$ & 4 & & \\
\hline & $\begin{array}{l}\text { Some schools are not working with the New Zealand } \\
\text { Curriculum (Technology) }\end{array}$ & 1 & & \\
\hline & Not confident with the revised curriculum & 1 & & \\
\hline \multirow[t]{6}{*}{26} & Technology teachers not trained in technology & 5 & 1.1 & 87.3 \\
\hline & No technology trained teachers apart from the HOD & 1 & & \\
\hline & Lots of teachers don't have technology backgrounds & 1 & & \\
\hline & $\begin{array}{l}\text { I support teachers teaching technology who are not } \\
\text { trained in it. }\end{array}$ & 1 & & \\
\hline & $\begin{array}{l}\text { Non trained tech teachers struggle to get students to } \\
\text { complete work }\end{array}$ & 1 & & \\
\hline & $\begin{array}{l}\text { Not worth spending much PD time on a teacher who only } \\
\text { teaches it for a few weeks in the year. }\end{array}$ & 1 & & \\
\hline \multirow[t]{6}{*}{27} & Teachers attitudes & 5 & 1.1 & 88.3 \\
\hline & Our teachers want to do best for the students. & 1 & & \\
\hline & Disillusioned teachers have left due to lack of support. & 1 & & \\
\hline & Teachers need to want to learn. & 1 & & \\
\hline & Negative teachers stop others from learning. & 1 & & \\
\hline & Staff shocked by negative teachers at meetings. & 1 & & \\
\hline \multirow[t]{5}{*}{28} & Beacon Practice successes & 5 & 1.1 & 89.4 \\
\hline & I got lots from being a Beacon Practice teacher & 2 & & \\
\hline & Beacon Practice PD was my only PD for the last 3 years & 1 & & \\
\hline & The exemplar material is embedded in the practice & 1 & & \\
\hline & Benchmark school gives good guidance & 1 & & \\
\hline \multirow[t]{4}{*}{29} & Cluster meetings are important & 5 & 1.1 & 90.5 \\
\hline & $\begin{array}{l}\text { Important to meet other teachers at subject association } \\
\text { meetings }\end{array}$ & 2 & & \\
\hline & Cluster meetings and conferences important. & 2 & & \\
\hline & $\begin{array}{l}\text { Regular technology area focused meetings to support } \\
\text { teachers are important }\end{array}$ & 1 & & \\
\hline
\end{tabular}




\begin{tabular}{|c|c|c|c|c|}
\hline Rank & Categories with content units & Frequency & $\%$ & $\begin{array}{c}\text { Cumulative } \\
\%\end{array}$ \\
\hline \multirow[t]{5}{*}{30} & Flexible & 5 & 1.1 & 91.6 \\
\hline & $\begin{array}{l}\text { PD most effective when facilitator is flexible to teacher } \\
\text { needs }\end{array}$ & 2 & & \\
\hline & $\begin{array}{l}\text { Allow teachers to be flexible with their approaches as a } \\
\text { result of professional development. }\end{array}$ & 1 & & \\
\hline & $\begin{array}{l}\text { Open flexible lesson plans which can be adopted by } \\
\text { teachers as a result of professional development. }\end{array}$ & 1 & & \\
\hline & $\begin{array}{l}\text { Students learning is limited if you aren't flexible as an } \\
\text { HOD. }\end{array}$ & 1 & & \\
\hline \multirow[t]{6}{*}{31} & Professional development opportunities in the past & 5 & 1.1 & 92.7 \\
\hline & PD on good teaching and pedagogy & 1 & & \\
\hline & I have had generic PD but not subject specific & 1 & & \\
\hline & G3+ PD was valuable & 1 & & \\
\hline & Whole school PD on pedagogy was good & 1 & & \\
\hline & I learned 'fly in five' at PD which has been useful & 1 & & \\
\hline \multirow[t]{4}{*}{32} & Reading is important & 5 & 1.1 & 93.8 \\
\hline & Reading the literature supports my practice & 3 & & \\
\hline & Teachers need to be active learners and do the readings & 1 & & \\
\hline & I've got used to the theory & 1 & & \\
\hline \multirow[t]{6}{*}{33} & Limited professional development opportunities & 5 & 1.1 & 94.9 \\
\hline & PD is limited to one day short courses & 1 & & \\
\hline & $\begin{array}{l}\text { I haven't yet had the opportunity to attend long } \\
\text { workshops }\end{array}$ & 1 & & \\
\hline & Not much junior technology professional development. & 1 & & \\
\hline & $\begin{array}{l}\text { Providers need better ways to inform teachers of PD } \\
\text { opportunities. }\end{array}$ & 1 & & \\
\hline & Teachers need support & 1 & & \\
\hline \multirow[t]{5}{*}{34} & School issues around PD & 4 & 0.9 & 95.8 \\
\hline & Principals need to be informed of teacher needs in PD & 1 & & \\
\hline & Compulsory PD for poor performing teachers & 1 & & \\
\hline & More timetable time for technology & 1 & & \\
\hline & $\begin{array}{l}\text { Permission from school and parents to trial new learning } \\
\text { approaches }\end{array}$ & 1 & & \\
\hline \multirow[t]{5}{*}{35} & Funding needed & 4 & 0.9 & 96.7 \\
\hline & $\begin{array}{l}\text { Funding for professional development not adequate to } \\
\text { meet the needs of teachers. }\end{array}$ & 1 & & \\
\hline & Funding for more advisory time needed. & 1 & & \\
\hline & $\begin{array}{l}\text { Better to pay teachers extra to attend professional } \\
\text { development during holidays. (saves missing classes) }\end{array}$ & 1 & & \\
\hline & $\begin{array}{l}\text { Too many needs to be covered in a limited number of } \\
\text { courses. (funding issue) }\end{array}$ & 1 & & \\
\hline \multirow[t]{5}{*}{36} & $\begin{array}{l}\text { Greater understanding of teaching practice in } \\
\text { technology }\end{array}$ & 4 & 0.9 & 97.6 \\
\hline & $\begin{array}{l}\text { Professional development helps teachers understand } \\
\text { technological practice. }\end{array}$ & 1 & & \\
\hline & $\begin{array}{l}\text { Better criteria for assessment as a result of professional } \\
\text { development. }\end{array}$ & 1 & & \\
\hline & $\begin{array}{l}\text { Technological practice has now got more knowledge in } \\
\text { the teaching. }\end{array}$ & 1 & & \\
\hline & NZC 2007 has been a focus. & 1 & & \\
\hline
\end{tabular}




\begin{tabular}{|c|c|c|c|c|}
\hline Rank & Categories with content units & Frequency & $\%$ & $\begin{array}{c}\text { Cumulative } \\
\%\end{array}$ \\
\hline \multirow[t]{5}{*}{37} & Professional development resources & 4 & 0.9 & 98.5 \\
\hline & Walk away from the PD with a resource & 1 & & \\
\hline & $\begin{array}{l}\text { PD needs to supply the information to make the job } \\
\text { easier and more manageable. }\end{array}$ & 1 & & \\
\hline & $\begin{array}{l}\text { NCEA Level } 3 \text { and scholarship exemplars in the past } \\
\text { have been useful }\end{array}$ & 1 & & \\
\hline & Teaching web site set up by teachers & 1 & & \\
\hline & Total 469 Content Units & & & \\
\hline & Categories & & & \\
\hline & & & & \\
\hline & Note: Error of $1.5 \%$ due to rounding to 1 decimal point. & & & \\
\hline
\end{tabular}




\title{
Appendix 2: Information sheet
}

\author{
VICTORIA UNIVERSITY OF WELLINGTON
}

Te Whare Wananga o te Upoko o te Ika a Maui

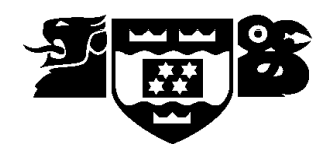

\section{Information Sheet}

\section{Project Title: From the perspective of technology heads of department and technology teachers, in what ways does teacher professional development support and improve technology teacher practice?}

This project aims to find out from secondary technology teachers what kind of professional development and learning they find most useful. I am seeking to find from the secondary teachers involved in the project the kinds of professional learning they have experienced in the past that has made a difference to their classroom practice, and what kinds of professional development they feel would most support their practice in the future.

Currently there is very little research in this area for technology teachers and I would like to ensure that the views of teachers are sought on this most important topic of their professional learning.

I hope that as a consequence of this research, I am able to inform schools, principals, PPTA, teacher professional development providers and other stakeholders about what works for secondary technology teachers. I intend to publish the outcomes in appropriate publications and journals that will inform the secondary teaching community. Your school will be provided with a copy of the research and notified as to publication.

I have randomly selected your school to be part of this project from schools in the Wellington region. I intend to gather data by means of conducting interviews with participants, recording responses to questions you will previously have considered and analyse the outcomes in order to make meaning of the responses.

I intend to interview 3 categories of teachers in order to get a cross section of perceived needs and views. These categories will be teachers with between $1-5$ years experience; teachers with $6-15$ years experience and heads of technology departments. I am optimistic that we will get a good understanding from this project of the kinds of professional development that work for teachers and would hope that principals, teachers and professional development providers everywhere will be interested in this knowledge.

I intend to use this knowledge to inform our practice when working in schools and the kinds of professional development we offer technology teachers.

Your participation in this research is entirely voluntary. It is expected that the interviews will take approximately $15-20$ minutes of your time in order to address the following key questions.

- How can technology teachers best be supported in their development and practice?

- What forms of professional development do technology teachers consider best supports and improves their practice? 
- In what ways do technology teachers view that effective professional development contributes to their practice?

- To what extent does teacher professional development facilitator (TPDF) practice influence the effectiveness of the professional development?

- What do heads of technology departments regard as most effective in supporting their technology teachers with changing their practice?

The responses recorded on audio tapes and subsequent transcriptions will remain confidential to the researcher. The data will be seen by the transcriber who will sign a confidentiality agreement. Once the data has been analysed, it will be destroyed to ensure confidentiality. The data will only be reported in aggregated format with no individual or school identifiable in any way. Some notes may be taken by the researcher at the meeting and you are most welcome to view these notes.

This project has been granted ethical approval by Victoria University College of Education Ethics Committee.

I hope that you are willing to give your consent to be part of this research by signing the Consent Form attached. Thank you

\begin{tabular}{l|l}
\hline Bruce Granshaw & Bruce.granshaw@vuw.ac.nz \\
Technology Education Professional Development & 044639636 \\
Facilitator/Lecturer, Victoria University of Wellington \\
College of Education
\end{tabular}




\title{
Appendix 3: Consent form for participating teachers
}

\author{
VICTORIA UNIVERSITY OF WELLINGTON \\ Te Whare Wananga o te Upoko o te Ika a Maui
}

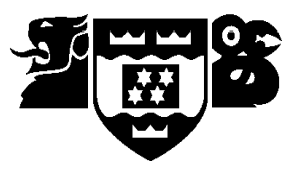

\section{Consent Form for Participating Teachers}

I have read the information on this research project and am willing to participate in a recorded interview in order to answer the research questions specified. I have understood the information provided and have been given an opportunity to seek further clarification and explanation. $\square$ (tick)

I understand that ethics approval has been obtained for this research and that my participation is voluntary and that my identity will be kept confidential and any reports from this project will not identify either me or my school in any way.

(tick)

I understand that upon completion of the research, all data (including audio tapes) will be destroyed and that my school will be given a copy of the outcome of the research and notified of its publication. $\square$ (tick)

A transcriber will see the data and sign a confidentiality agreement. $\square$ (tick)

Name:

$\square$ (tick) I am willing to participate.

Signature:

Date: 